Document downloaded from:

http://hdl.handle.net/10251/166958

This paper must be cited as:

Zubel, MG.; Fasano, A.; Woyessa, GT.; Min, R.; Leal-Junior, AG.; Theodosiou, A.; Marques, CAF... (2020). Bragg Gratings Inscribed in Solid-Core Microstructured Single-Mode Polymer Optical Fiber Drawn From a 3D-Printed Polycarbonate Preform. IEEE Sensors Journal. 20(21):12744-12757. https://doi.org/10.1109/JSEN.2020.3003469

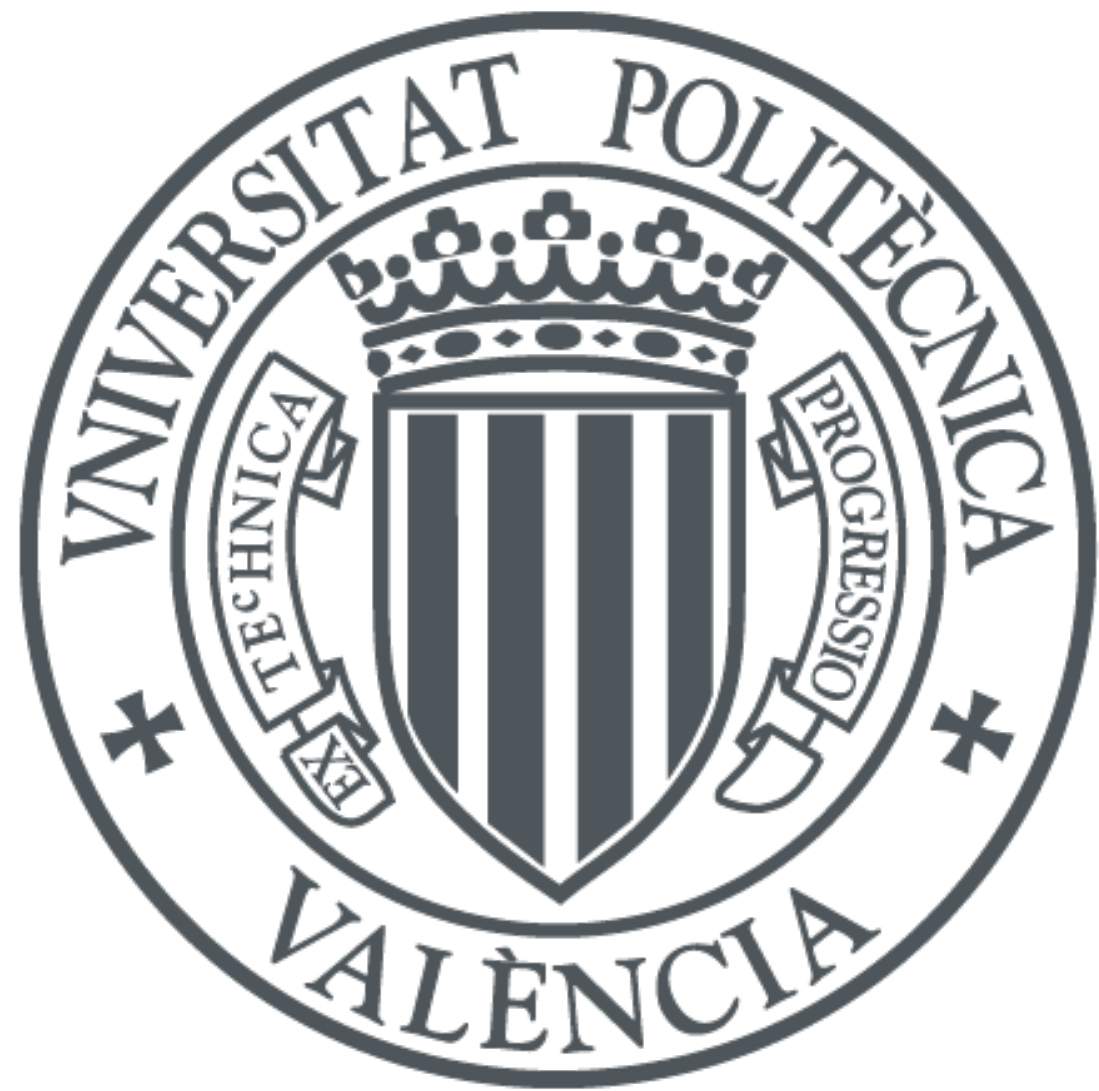

The final publication is available at

https://doi.org/10.1109/JSEN.2020.3003469

Copyright Institute of Electrical and Electronics Engineers

Additional Information 


\title{
Bragg gratings inscribed in solid-core microstructured single-mode polymer optical fiber drawn from a 3D-printed polycarbonate

\author{
preform
}

\author{
Michal G. Zubel, Andrea Fasano, Getinet Woyessa, Rui Min, Arnaldo Leal-Junior, Antreas \\ Theodosiou, Carlos A.F. Marques, Henrik K Rasmussen, Ole Bang, Beatriz Ortega, Kyriacos \\ Kalli, Anselmo Frizera-Neto, Maria José Pontes, and Kate Sugden
}

\begin{abstract}
This paper reports the first microstructured solid-core fiber drawn from a 3D-printed preform and the first fiber Bragg gratings inscribed in a fiber of this type. The presented fiber is made of polycarbonate and displays single-mode behavior. The fiber attenuation was the lowest reported so far for a POF drawn from a 3D-printed preform across a broad range of wavelengths. In addition, extensive fiber characterization results are presented and discussed including: fiber attenuation, mode simulations, dynamic thermomechanical analysis and thermo-optic coefficient. Fiber Bragg gratings are successfully inscribed in the produced fiber using three different lasers: a continuous wave helium-cadmium laser, a pulsed femtosecond frequency doubled ytterbium laser and ultra-violet nanosecond krypton fluoride laser. Mechanical testing of the fiber showed that the 3D printing approach did not introduce any unexpected or undesirable characteristics.

Index Terms - Fiber optics sensors, fiber Bragg gratings, microstructured fibers, fiber characterization, additive layer manufacturing, 3D printing, fused deposition modeling.
\end{abstract}

\section{Introduction}

$\mathrm{T}$ HE group of techniques commonly described as 3D printing or additive layer manufacturing (ALM) have been revolutionizing the field of manufacturing and rapid

Date submitted for review: XX December 2019. The research leading to these results has received funding from the People Program (Marie Curie Actions) of the European Union's Seventh Framework Program FP7/2007-2013/ under REA grant agreement $n^{\circ}$ 608382. C. A. F. Marques acknowledges FCT through the program UID/CTM/50025/2019 and SAICTPAC/0036/2015 and by the National Funds through the Fundação para a Ciência e a Tecnologia / Ministério da Educação e Ciência, and the European Regional Development Fund under the PT2020 Partnership Agreement. This work is also funded by national funds (OE), through FCT - Fundação para a Ciência e a Tecnologia, I.P., in the scope of the framework contract foreseen in the numbers 4,5 and 6 of the article 23, of the Decree-Law 57/2016, of August 29, changed by Law 57/2017, of July 19 .

M. G. Zubel is with Aston Institute of Photonic Technologies, Aston University, Birmingham, B4 7ET, UK (e-mail: zubelmg@aston.ac.uk).

A. Fasano is with Department of Mechanical Engineering, Technical University of Denmark, DK-2800 Kgs. Lyngby, Denmark (e-mail: andfas@mek.dtu.dk).

G. Woyessa is with Department of Photonics Engineering, Technical University of Denmark, DK-2800 Kgs. Lyngby, Denmark (e-mail: gewoy@fotonik.dtu.dk).

R. Min is with ITEAM Research Institute, Universitat Politècnica de València, Valencia, Spain (e-mail: rumi@doctor.upv.es).

A. Leal-Junior is with Telecommunications Laboratory (LABTEL), Electrical Engineering Department, Federal University of Espírito Santo, Fernando Ferrari avenue, 29075-910, Vitória-ES, Brazil (e-mail: lealjunior.arnaldo@ieee.org). prototyping in recent years and are increasingly envisioned as the manufacturing techniques of the future $[1,2]$. Among their advantages lie the rapidly increasing quality of fabricated parts; ease and speed of customizability; decreasing price; ability to

A. Theodosiou is with Photonics and Optical Sensors Research Laboratory, Cyprus University of Technology, Limassol 3036, Cyprus (e-mail: theodosiou.antreas@gmail.com).

C. A. F. Marques is with I3N \& Physics Department, Universidade de Aveiro, Campus Universitário de Santiago, 3810-193 Aveiro, Portugal (e-mail: carlos.marques@ua.pt).

H. K. Rasmussen is with Department of Mechanical Engineering, Technical University of Denmark, DK-2800 Kgs. Lyngby, Denmark (email: hkra@mek.dtu.dk)

O. Bang is with Department of Photonics Engineering, Technical University of Denmark, DK-2800 Kgs. Lyngby, Denmark (e-mail: oban@fotonik.dtu.dk).

B. Ortega is with ITEAM Research Institute, Universitat Politècnica de València, Valencia, Spain (e-mail: bortega@dcom.upv.es).

K. Kalli is with Photonics and Optical Sensors Research Laboratory, Cyprus University of Technology, Limassol 3036, Cyprus (e-mail: kyriacos.kalli@cut.ac.cy).

A. Frizera-Neto is with Telecommunications Laboratory (LABTEL), Electrical Engineering Department, Federal University of Espírito Santo, Fernando Ferrari avenue, 29075-910, Vitória-ES, Brazil (e-mail: frizera@ieee.org).

M. J. Pontes is with Telecommunications Laboratory (LABTEL), Electrical Engineering Department, Federal University of Espírito Santo, Fernando Ferrari avenue, 29075-910, Vitória-ES, Brazil (e-mail: mjpontes@ele.ufes.br).

K. Sugden is with Aston Institute of Photonic Technologies, Aston University, Birmingham, B4 7ET, UK (e-mail: k.sugden@aston.ac.uk). 
reproduce complex shapes that are difficult to manufacture otherwise; and a growing number of printing materials which offer ever more potential applications.

Fused deposition modelling (FDM) is the most popular 3D printing approach. It starts with melting thermoplastic filament in a hot printing nozzle. Subsequently, the resulting semi-liquid material is pushed through the printing nozzle and deposited in the desired location for the model being printed. After leaving the printing nozzle, the molten material cools down and solidifies to build up the manufactured object layer by layer.

In theory, FDM should be intrinsically well-suited for manufacturing fiber preforms for the production of polymer optical fibers (POFs), as the basic material requirement for both POF preforms and FDM filament is thermoplasticity. The biggest advantage of using the FDM technique for fabricating POF preforms is ease of reproducing complex shapes that would be very difficult to manufacture with other methods such as drilling techniques. Moreover, FDM offers the broadest printing material range of all ALM techniques. In addition, printing polymers can be mixed within one preform printout, which allows for the potential tuning of the material properties (including refractive index, transparency, chemical composition, flexibility, biodegradability, coefficient of thermal expansion, affinity to water etc.).

The qualities of FDM applied to POF manufacturing (predominantly for visible and infrared range) have already been recognized, leading to several interesting publications in the recent years. A step-index fiber was drawn from a preform made of two polymers, printed on a dual-head 3D printer [3]. The core of this fiber was made of styrene-butadiene copolymer and polystyrene (SBP) and cladding of modified polyethylene terephthalate glycol (PETG). In [4], cores of various shapes (made of polycarbonate, PC) and complementary claddings (made of acrylonitrile butadiene styrene, ABS) were printed separately and assembled together to form preforms, which were subsequently drawn. This demonstrated the ease at which 3D-printed shapes and hence fiber properties could be customized. Air-structured fiber drawn from a 3D-printed preform made of SBP was presented in [5]. Hollow-core 3Dprinted POF preforms have also been reported. The first one proposed was made of poly(methyl methacrylate) (PMMA) and drawn to cane stage [6], and the first HC POF drawn from 3Dprinted preform was made of ABS [7]. This was followed by a publication on mid-IR HC microstructured POF (mPOF) drawn from 3D-printed preform made of PETG [8]. Coreless POFs drawn directly from 3D printer nozzle were reported in [9], in which preform stage in POF manufacturing was omitted. In addition, larger $\mathrm{THz}$ waveguides have been directly 3D-printed at the size required for use $[10,11,12]$.

The aim of this work is to advance further POF manufacturing research with regards to the $3 \mathrm{D}$ printing of preforms and demonstrate the feasibility of fabricating singlemode microstructured solid-core fibers in order to further understand some of the limiting factors associated with the technology. This opens up the opportunity for complex perform designs, comprising of single or multiple materials, that are difficult to realize with conventional techniques to be directly printed in a single-stage process. For example, with hollowcore fibers this could include hollow-core negative curvature fibers that contain nested elements, ellipses or half-ellipses, which have been modelled but are not feasible to make with conventional fabrication methods. The work also aims to produce a fiber suitable for the inscription of fiber Bragg gratings at $870 \mathrm{~nm}$ and $1560 \mathrm{~nm}$. Extensive fiber characterization results are presented in order to understand the properties of the fiber.

The prototype preform was printed using PC, which has previously been used to successfully fabricate POFs using the drill-and-draw technique $[13,14]$. PC was chosen due to the highest glass transition temperature $\left(145^{\circ} \mathrm{C}\right)$ and highest operational temperature $\left(125^{\circ} \mathrm{C}\right)$ of all POF materials reported so far $[13,14]$. For reference, the highest reported operational temperature of Topas 5013S-04 is $110^{\circ} \mathrm{C}$ [15], of Zeonex 480R is $100^{\circ} \mathrm{C}$ [16] and of PMMA (the most popular POF material) is $92^{\circ} \mathrm{C}$ [17]

Dynamic mechanical analysis (DMA) was used to evaluate the mechanical characteristic of the fiber. DMA is a wellestablished method for polymer characterization used in different fields including industrial [18], automotive [19], aircraft [20] and biological applications [21]. In this technique, a sample is fixed at one end, and an oscillatory tensile load is applied on the other. This results in performing sequential strain cycles with controlled frequency and displacement. Moreover, the method can also involve temperature variation. This then allows evaluating dependency of Young's modulus of sample on all the mentioned parameters (strain, temperature and strain cycle frequency). Such analysis has previously been used to characterize POFs of various structures and made of different materials, including PMMA microstructured polymer optical fibers (mPOFs) [22], PMMA step-index fibers [23], mPOFs of different materials (Topas 5013S-04, Zeonex 480R, polycarbonate) [24], and CYTOP graded-index fibers [25].

Despite still being considered an emerging family of optical fiber sensors (OFSs), polymer optical fiber Bragg gratings (POFBGs) [26] have been attracting growing attention. They share common advantages of OFSs, which include: being lightweight, small and potentially low cost; ease of integration with existing fiber optic networks; the potential for use in many applications for which electronic sensors are intrinsically unsuitable such as in harsh, flammable and explosive environments; ease of multiplexing; immunity to electromagnetic interference; remote interrogation ability POFBGs are often contrasted with silica optical fiber Bragg gratings (silica FBGs or SOFBGs) in order to highlight their particular qualities. These entail much lower elastic modulus (3.3 GPa for POFBGs made of PMMA compared to $73 \mathrm{GPa}$ for SOFBGs); much higher yield strength resulting in greater strain sensing range; biocompatibility and biodegradability; flexibility in modification of chemical composition and structure, allowing fine tuning of the fiber material properties e.g. to make it sensitive or insensitive to water [26].

POFBGs are capable of sensing various parameters e.g.: strain $[27,28,29,30]$, bend [31], other mechanical deformation $[32,33]$, temperature $[27,28,34]$, humidity $[14,35,36]$, pressure [33, 37, 38, 39], refractive index [40] and acceleration [41]. The most used material for fabricating POFBGs is PMMA $[27,28]$. However, POFBGs have been successfully manufactured in several other polymer types: polycarbonate 
(PC) [14], Topas [42, 43], Zeonex [16] and CYTOP [31]. The application of POFBGs has been demonstrated in a number of fields including: medicine [44, 45, 46], biochemistry [40], aviation $[47,48]$, dosimetry [49], cultural heritage preservation [50] and integration with textiles [50].

Inscribing FBGs in POFs drawn from 3D-printed preforms is potentially very attractive in terms of being able to further broaden application range of POFBGs through the use of bespoke fiber designs for particular applications.

The paper commences with describing research leading to optimization of transparency of 3D printouts made of PC. Based on this work, a POF preform is printed and characterized. Secondly, preform post-processing and fiber drawing is presented. The resulting POF is characterized, which include cleaving and light coupling to core, modelling of the propagation, cut-back attenuation measurements and dynamic thermomechanical analysis. Finally, FBGs inscribed with different lasers and techniques are shown and characterized, and the thermo-optic coefficient of the fiber is calculated.

\section{Preform and Fiber Fabrication}

\section{A. Transparency Optimization of 3D Printouts}

All preforms described in this paper were produced using an UP! Plus 3D printer (model 3DP144A) and its proprietary slicer software with the FixUp3D extension. Commercially available PC filament of $1.75 \mathrm{~mm}$ diameter was used (manufactured by Dr3DFilament).

Before 3D-printing the preform, the printing parameters had to be optimized so as to achieve maximal transparency of the printed structure. The biggest challenge lies in air being trapped between thread lines during the fabrication process, which results in light scattering defects being created in preform. Transparency optimization relies then on ensuring that adjacent thread lines melt together well with no air voids between them.

To optimize the transparency a series of thin $(4 \mathrm{~mm})$ circular samples of diameter equal to the preform $(65 \mathrm{~mm})$ were printed. The key printing parameters were varied, including the printing speed (speed of movement of printing nozzle), filament feed rate and nozzle temperature. The values for layer thickness, nozzle diameter and printing bed temperature were kept constant. After printing, the samples were polished from top, bottom and side, and the transparency was evaluated visually.

The printing speed was varied from 5 to $20 \mathrm{~mm} / \mathrm{s}$. Generally, lower printing speeds resulted in better transparency (see Fig. 1) probably due to heat transfer from nozzle to printout. The higher the temperature, the better the infill threads melt together, and the lower printing speed allows a given region of printout to absorb more heat from nozzle as it approaches before the material is deposited. Such a mechanism would also explain the difference in transparency between the samples printed on heated $\left(105^{\circ} \mathrm{C}\right)$ and non-heated printing bed (compare Fig. 1 (c) and (d)).

The layer thickness was set to $150 \mu \mathrm{m}$, and diameter of the nozzle used was $300 \mu \mathrm{m}$. It had been found previously that the optimal printing temperature from the viewpoint of transparency for PMMA was $280-290^{\circ} \mathrm{C}$ [6]. Due to its higher melting point, $\mathrm{PC}$ would ideally be printed at higher nozzle temperatures than PMMA. Consequently, the nozzle temperature was fixed at temperature was fixed at $300^{\circ} \mathrm{C}$, which was the maximum settable value for the $3 \mathrm{D}$ printer used.

When varying the filament feed rate, an optimum speed was identified, while both too high and too low values were found to decrease transparency. Too low values resulted in volume of printout not being fully filled in. Too high feed rates made excessive material aggregate on printout walls which in turn lowered the printing accuracy and hindered operation of the printer.

\section{B. Fabrication of the Preform}

The rationale behind the initial preform design was to make it as easy as possible to be reliably reproduced by the printer. Consequently, a two-ring structure in a hexagonal arrangement was printed (top view shown in Fig. 2(a)), which has previously been shown to guide light [51]. The hole diameter (d) was set to $6 \mathrm{~mm}$ and the hole pitch $(\Lambda$, distance between centers of adjacent holes) to $12 \mathrm{~mm}$. The preform diameter and height were $65 \mathrm{~mm}$ and $105 \mathrm{~mm}$, respectively. Before drawing, the preforms were machined down to $60 \mathrm{~mm}$ and $100 \mathrm{~mm}$, respectively.

The preform (Fig. 2) was printed at a speed of $5 \mathrm{~mm} / \mathrm{s}$ (other settings were the same as in Section II.-A), taking 323 hours in total and using $291.7 \mathrm{~g}$ of material. The printout warped a little during printing (the sides of the raft detached from the printing bed), resulting in a slightly rounded bottom surface. In the case of this preform, warping was not an issue, because it did not distort the designed geometry above the bottom surface. The quality of the top and bottom sections is not overly important, since they are sacrificed during fiber drawing stage.

\section{Preform Post-Processing and Fiber Drawing}

The finished preform was annealed in a conventional oven at $130^{\circ} \mathrm{C}$ for 4 weeks to remove air bubbles trapped in preforms and hence increases transparency [3,5]. It was then machined in order to remove surface roughness and make it suitable for cane drawing using the polymer draw tower. The resulting length and outer diameter were $100 \mathrm{~mm}$ and $60 \mathrm{~mm}$, respectively. The preform was then further annealed prior to drawing for 4 more weeks under the same conditions.

The fiber was produced using the two-step heat and draw method [51] where first, the preform was drawn into intermediate canes at a temperature of $180^{\circ} \mathrm{C}$. The canes were $6 \mathrm{~mm}$ in diameter and $50 \mathrm{~cm}$ in length. Each cane was subsequently inserted in a PC sleeving tube. The resulting composite canes were annealed for 10 days at $130^{\circ} \mathrm{C}$ to ensure that any bubbles trapped in the sleeving tube and cane were removed. Then, one of the composite canes was drawn to fiber at a temperature of $185^{\circ} \mathrm{C}$. In the remaining part of the text, the resulting fiber is referred to as $3 \mathrm{D}$ PC $\mathrm{mPOF}$.

\section{FIBER CHARACTERIZATION}

\section{A. Fiber cleaving and light coupling to core}

Fig. 3(a) shows a microscopic image of a cleaved facet of the 3D PC mPOF. The darker inner region corresponds to the preform, and the lighter outer one corresponds to the sleeving tube. In the magnified image (Fig. 3(b)), the core is clearly visible. The literature reports the optimal cleaving temperature for a $\mathrm{PC} \mathrm{mPOF}$ fiber to be $80^{\circ} \mathrm{C}[13,14]$. In this instance a 
temperature of $75^{\circ} \mathrm{C}$ yielding the best cleave quality for the temperatures tested where both the fiber and the blade were heated. However, this temperature was possibly a little too high for this fiber as can be inferred from the slight ellipticity of the microstructure holes [52]. In this research, fiber cleaving was performed manually using a blade and a hot plate, which only gave limited control over the process. Further optimization of cleaving temperature was not undertaken as the cleave quality was found enough for light coupling. Such optimization often involves specialized cleaving apparatus and is a separate research question $[52,53,54]$ beyond the scope of this work.

Red light from a fiber-coupled semiconductor laser (wavelength $\sim 638 \mathrm{~nm}$, optical power $\sim 2.5-5.0 \mathrm{~mW}$ ) was buttcoupled into the fiber (fiber length $=38.1 \mathrm{~mm}$ ) and projected onto a screen (experimental setup in Fig. 4) to observe the clear core guidance, shown in Fig. 3(c). Core guidance was visible by eye over fiber lengths of $\sim 10 \mathrm{~cm}$. For this wavelength of light, only cladding guidance from the outer tube was observed at longer fiber lengths (see Fig. 3(d)).

\section{B. Simulation of the Confinement Loss and Modality of the Fiber}

For a microstructured fiber to display endlessly single-mode behavior, the $d / \Lambda$ ratio should be less than 0.406 [55]. Here the chosen dimensions of hole diameter and pitch of the preform would result in $d / \Lambda=0.5$. After drawing, the geometry of the fiber changed and the average diameter of the holes in the inner ring $\left(d_{\text {ina }}\right)$ was visibly higher than of those in the outer ring $\left(d_{\text {out }}\right)$. The measured geometry was: $d_{\text {war }}=2.7 \mu \mathrm{m}, d_{\text {our }}=1.45 \mu \mathrm{m}, \Lambda=$ $5.4 \mu \mathrm{m}$ (see Fig. 3(b)).

For non-endlessly single-mode mPOF, there is no strict criteria to differentiate single-mode and multi-mode behavior. As opposed to step index fibers, all modes in microstructured optical fibers have some non-zero confinement loss due to finite number of microstructure rings. However, a large enough number of rings (often 8 ) ensures that the confinement loss is negligible compared to other loss mechanisms [51, 56]. Hence, fiber modality is often designated based on acceptable value of loss for a particular application, and in the case of high loss for second mode, fiber can be considered "essentially" singlemode. A useful approximation of the cut-off wavelength based on fiber geometrical parameters was presented in [55]. There, the cut-off wavelength was defined as the transition between delocalized single mode (the second mode not being localized in core) and localized multimode behavior (second and possibly higher order modes localized in core). However, this cut-off wavelength was defined for an ideal silica fiber made of 8 rings of even holes.

In order to assess the confinement loss and modality of the fiber, COMSOL (v. 4.3) [57] and CUDOS (v. 2) [58, 59, 60] software packages were used to run simulations on the described geometry. They gave very similar results regarding real part of effective refractive index $\left(\operatorname{Re}\left(n_{t f}\right)\right)$ and modal patterns, while CUDOS seemed to provide higher precision of imaginary part of $n_{t f}\left(\operatorname{Im}\left(n_{t f}\right)\right)$. Simulations were performed for the two wavelengths $(870 \mathrm{~nm}$ and $1550 \mathrm{~nm}$, see Fig. 5 and Table I) at which FBGs were inscribed (Section IV). Material refractive indexes used were 1.577 and 1.567 , respectively [13]. Simulations at $1550 \mathrm{~nm}$ resulted in virtually the same plots as at $870 \mathrm{~nm}$ (Fig. 5).

Modes of microstructured fibers follow patterns of stepindex modes only approximately. The step-index fiber naming convention (HE, EH, TM, TE) does not work for more complex mode shapes and so designation of modes based on symmetries is used instead [61]. The symmetry group of 3D PC mPOF is $\mathrm{C}_{6 \mathrm{ov}}$. This gives 8 classes of modes: 4 non-degenerate ones $(1,2$, $7,8)$ and two pairs of two-fold degenerate classes ( 3 and 4,5 and 6).

From simulation, the confinement loss of the second mode was found to be much larger than the fundamental mode at both $870 \mathrm{~nm}$ and $1550 \mathrm{~nm}$ (220 times and 122 times, respectively). The second least lossy mode at both wavelengths (equivalents of $E_{x_{23}}$ and $E_{y_{23}}$ modes from step-index rectangular symmetry) showed losses 41 times higher $(870 \mathrm{~nm})$ and 48 times higher $(1550 \mathrm{~nm})$ than the fundamental. These values imply that the confinement loss would prevent higher order modes from propagating over more than a few $\mathrm{cm}$, while guiding the fundamental mode over hundreds of $\mathrm{cm}$. Hence, 3D PC mPOF can be considered single-moded at both $870 \mathrm{~nm}$ and $1550 \mathrm{~nm}$. Effective single-mode behavior can also be inferred from modal field patterns (Fig. 5), which show that the second mode is not fully localized. This is evident in electric field magnitude plot and is supported by the relatively high loss value.

To investigate fiber modality further, fiber parameters were compared with [55] to check whether the fiber is in delocalized single mode or localized multimode operation region. For comparison, the hole diameter was averaged over both inner and outer ring of the actual geometry to give the following: $d=$ $2.4 \mu \mathrm{m}, \Lambda=5.4 \mu \mathrm{m}, d / \Lambda=0 . \overline{4}$. These results compared to [55] also suggest the fiber is in delocalized single mode operation at $870 \mathrm{~nm}$ and $1550 \mathrm{~nm}$

\section{Fiber Attenuation Measurements}

The fiber attenuation was measured using the cut-back method [62]. Light from a supercontinuum source (Fianium White laser WL-SC-400) was launched via a silica fiber into one end of the 3D PC mPOF under test. The two fibers were fixed together using a ceramic ferrule. The other end of the $3 \mathrm{D}$ $\mathrm{PC} \mathrm{mPOF}$ was placed in a second ceramic ferrule and connected directly to an optical spectrum analyzer (OSA). Two OSAs were used: a Yokogawa AQ6373B for the wavelength range 400-1200 nm and a Yokogawa AQ6370 for the 1200-2400 nm range. Transmission spectra were recorded for 7 fiber lengths, starting at $86 \mathrm{~cm}$ and finishing at $26 \mathrm{~cm}$, giving $10 \mathrm{~cm}$ length decrements between measurements. In order to minimize the end face influence and maximize transmission, a few spectra were recorded for every fiber length after shortening the fiber by a small amount (1-2 $\mathrm{mm})$ and the maximal transmission spectra for each length is shown in Fig. 6.

Due to the low transmission power for the longer fiber lengths only the data from the three shortest fiber lengths (26, 36 , and $46 \mathrm{~cm}$ ) was used for calculating the attenuation. The short lengths present a challenge because it then becomes difficult to remove cladding modes by bending the fiber and so it should be noted that the data given is for all modes of the fiber. For each spectral point, the attenuation plot (Fig. 7) shows the slope resulting from the linear regression (least squares method) of the 26,36 , and $46 \mathrm{~cm}$ data series. In some 
spectral regions (1110-1205 nm, 1340-1435 nm, 1729-1747 $\mathrm{nm})$, the calculated attenuation curve was very noisy due to bands of high material absorption, and hence the results in those regions are not credible. The data in the spectral region below $550 \mathrm{~nm}$ was discarded due to low light source intensity. The shape of the attenuation spectrum seems to align well with [13], except for wavelengths below $750 \mathrm{~nm}$, which is the range that would be more susceptible to scattering losses at the airpolymer interface in the hole region.

The lowest attenuation of $\sim 0.27 \mathrm{~dB} / \mathrm{cm}$ for $3 \mathrm{D}$ PC mPOF is found in a few spectral regions $(780-785 \mathrm{~nm}, 820-825 \mathrm{~nm}, 953$ $956 \mathrm{~nm}, 1070-1090 \mathrm{~nm}$ ). Attenuation calculated in Fig. 7 is the lowest reported in the literature so far for solid-core POFs (including step index ones) drawn from 3D-printed preform at any wavelength (see Table II). However, Table II also shows that losses for fibers drawn from mechanically casted and drilled PC preforms are up to 8 times lower, which leaves room for optimization.

Compared to simulations in Section III.-B, it can be noted that confinement loss $(\sim 0.11 \mathrm{~dB} / \mathrm{cm})$ accounts for $\sim 22 \%$ of total loss at $870 \mathrm{~nm}(\sim 0.50 \mathrm{~dB} / \mathrm{cm})$. This ratio changes at $1550 \mathrm{~nm}$, where confinement loss contributes as much as $\sim 63 \%$ $(\sim 0.44 \mathrm{~dB} / \mathrm{cm})$ of the total loss $(\sim 0.69 \mathrm{~dB} / \mathrm{cm})$ although for the measurement the noise level at $1550 \mathrm{~nm}$ is relatively high.

\section{Dynamic mechanical analysis of the fiber}

Dynamic mechanical analysis (DMA) was performed on the 3D PC mPOF to evaluate the Young's modulus with respect to temperature and strain cycle frequency (following standard ASTM D4065), and thermal expansion coefficient of the fiber (standard ASTM E831-14). The equipment used for the stressstrain cycles in the strain limit up to $11 \%$ was a DMA 8000 (Perkin Elmer, USA).

The first test performed was the implementation of a series of stress-strain cycles, which allowed the Young's modulus of the 3D PC mPOF at room temperature to be estimated as $2.47 \pm 0.10 \mathrm{GPa}$ (determination coefficient $\mathrm{R}^{2}=0.9979$ ) - see Fig. 8. The confidence interval (CI) for measurement errors throughout this section is $95 \%$, unless otherwise noted. The Young's modulus was estimated through the slope of the linear region of the stress-strain curve (in the range 0.05-0.3\%). From Fig. 8 , it is also possible to estimate yield stress, which is stress at which stress-strain curve shows non-linear behavior. Such non-linear behavior was noted for the stress higher than about $60 \mathrm{MPa}$. Yield stress is within the range for the PC material (59$70 \mathrm{MPa}$ [63]), while Young's modulus slightly exceeds its upper range value (2-2.44 GPa [63]). Moreover, the Young's modulus obtained for the 3D PC mPOF is close to the one estimated for the drilled-preform 3-ring PC mPOF in [24] $(2.89 \pm 0.30 \mathrm{GPa})$ and [64] $(2.70 \pm 0.01 \mathrm{GPa})$.

In the Young's modulus characterization with respect to temperature, the strain cycle frequency used was $1 \mathrm{~Hz}$, while temperature was varied from $25^{\circ} \mathrm{C}$ to $140^{\circ} \mathrm{C}$. The strain range was $0-0.2 \%$. The 3D PC mPOF exhibits a linear decrease of its Young's modulus with respect to a temperature increase with a slope of $-4.775 \pm 0.094 \mathrm{MPa} /{ }^{\circ} \mathrm{C}\left(\mathrm{R}^{2}=0.9968\right.$; see Fig. 9(a) $)$. The maximum Young's modulus variation is similar to that obtained in [24] for a drilled PC mPOF (about 0.5 GPa). However, for the 3D PC mPOF, the Young's modulus decrease shows higher linearity than in [24].
Fig. 9(b) shows the Young's modulus variation with respect to strain cycle frequency. The temperature was about $27^{\circ} \mathrm{C}$, the frequency range was $0.01-10 \mathrm{~Hz}$, and the strain range was 0 $0.5 \%$. The fiber exhibits an increase of Young's modulus with frequency until $5 \mathrm{~Hz}$, after which sharp decrease of Young's modulus is noted. Such behavior was also observed for PMMA, Topas 5013, Zeonex 480R, and PC mPOFs in [24]. However, in the case of the 3D PC mPOF, the Young's modulus variation with respect to frequency is higher, and the slope of $302 \pm 14 \mathrm{MPa} / \log _{\mathrm{o}}(\mathrm{Hz})\left(\mathrm{R}^{2}=0.9959\right)$ was obtained in the range 0.01-5 Hz. This seems to contradict the results reported in [64], showing no Young's modulus dependence on frequency, which might be due to different measurement equipment.

Finally, the linear thermal expansion coefficient (linear CTE, LCTE) of the 3D PC mPOF was evaluated using TMA mode of the DMA 8000 device. A small constant tensile load $(F=$ $0.01 \mathrm{~N}$ ) was applied on the fiber, and fiber strain was observed while changing temperature (see Fig. 10). Total variation of fiber strain $\left(\varepsilon_{v w i}\right)$ with temperature was ascribed to two factors, thermal expansion $\left(\varepsilon_{\text {IF }}\right)$ and different response to stress caused by tensile load $\left(\varepsilon_{\sigma}\right)$, coming from dependence of Young's modulus on temperature (measured earlier):

$$
\varepsilon_{\text {total }}(\Delta T)=\varepsilon_{T E}(\Delta T)+\varepsilon_{\sigma}(\Delta T)
$$

In the TMA method, $\varepsilon_{\sigma}$ can often be neglected because it normally is much smaller than $\varepsilon_{\text {гв }}$ due to very small value of force from tensile load. However, in the case of this fiber, $\varepsilon_{\text {wat }}$ was found to be so small that neglecting $\varepsilon_{\sigma}$ would deviate the value of LCTE. $\varepsilon_{\sigma}$ and $\varepsilon_{\pi}$ can be written as:

$$
\begin{gathered}
\varepsilon_{T E}(\Delta T)=\alpha_{\|} \cdot \Delta T \\
\varepsilon_{\sigma}(\Delta T)=\frac{\sigma}{E(\Delta T)}-\frac{\sigma}{E_{0}}=\frac{\sigma}{\frac{d E}{d T} \cdot \Delta T+E_{0}}-\frac{\sigma}{E_{0}}
\end{gathered}
$$

where: $\alpha / /\left({ }^{\circ} \mathrm{C}^{-1}\right)$ is the linear $\mathrm{CTE}$ along the fiber axis, $\Delta T\left({ }^{\circ} \mathrm{C}\right)$ is the temperature change above the initial temperature of the experiment $\left(T_{o}=27.10 \pm 0.01^{\circ} \mathrm{C}\right), \sigma=F / A(\mathrm{~Pa})$ and is the stress on the fiber coming from tensile load $F=0.01 \pm 0.002 \mathrm{~N}$ acting on fiber area $A\left(\mathrm{~m}^{2}\right), E(\Delta T)=d E / d T \cdot \Delta T+E_{o}(\mathrm{~Pa})$ and is the Young's modulus of the fiber, $d E / d T\left(\mathrm{~Pa} /{ }^{\circ} \mathrm{C}\right)$ is the dependence of Young's modulus on temperature, and $E_{v}(\mathrm{~Pa})$ is the Young's modulus at $T_{0}$. In (3), subtraction of the second term $\left(\sigma / E_{0}\right)$ is required to make $\varepsilon_{s}$ start from zero at $T_{o}$.

By measuring the cross-sectional area of the fiber from the microscope image $\left(A=22,500 \pm 500 \mu \mathrm{m}^{2}\right), \sigma$ was estimated to be $4.45 \pm 0.98 \times 10^{\circ} \mathrm{Pa}$. This stress caused the fiber to be prestrained by $175 \pm 39 \mu \varepsilon$ at the beginning of the experiment (at $T_{0}$ ), which is the value of the second term $\left(\sigma / E_{o}\right)$ in (3). Changes to $\varepsilon$ coming from decrease of cross-sectional area of the fiber upon straining were found to be very small and hence were neglected. Based on the experiment described earlier (see Fig. 9), $d E / d T$ and $E_{0}$ were calculated to be $-4.775 \pm 0.094 \mathrm{MPa} /{ }^{\circ} \mathrm{C}$ and $2.5479 \pm 0.0084 \mathrm{GPa}$, respectively. Inserting these values to (1)(3) allowed to plot $\varepsilon_{s}$ and $\varepsilon_{\text {п }}$ along with the experimental values of $\varepsilon_{\text {wat }}$ in Fig. 10. The value of LCTE along the fiber axis $(\alpha / /)$ coming from linear regression was $7.34 \pm 0.53 \times 10^{-{ }^{\circ}} \mathrm{C}^{-1}(\mathrm{CI}=$ $95 \%)$.

This LCTE is about two orders of magnitude smaller than those usually encountered in the literature for PC material, which are in the range of $5.0-8.1 \times 10^{-5}{ }^{\circ} \mathrm{C}^{-1}$ (in bulk as well as in 
the form of thin films and pellets) $[65,66,67,68,69,70,71]$ For this reason, special care was taken to ascertain the obtained value is accurate. The calculated LCTE value was crossvalidated by manual calculations to check the experimental error yielded by the total differential method and gave the result of $7.3 \pm 1.5 \times 10^{-7} \mathrm{C}^{-1}$. The larger experimental error obtained does not change the two orders of magnitude difference between the calculated value and the literature ones.

Some studies on POFs assume the literature LCTE values for bulk polymer to be valid $[72,73,74,75]$. However, research by Zhang and Webb [76], tackling specifically the CTE of POF (made of PMMA), revealed its anisotropic behavior. According to their paper, the anisotropic nature of POF is caused by drawing process, during which polymer molecules tend to be preferentially aligned along drawing direction. This has been shown for a range of mPOFs drawn from different polymers, including PC, in [64]. Such molecular alignment in POF results in anisotropy of LCTE, making the LCTE value along drawing direction $\left(\alpha_{/ /}\right)$lower than for the isotropic material $\left(\alpha_{i s}\right)$ normally reported in the literature. Consequently, the value of LCTE perpendicular to drawing direction $\left(\alpha_{\perp}\right)$ is higher than $\alpha_{\text {io }}$. Such behavior is well-known in the field of oriented polymers $[76,77,78,79]$, and should apply equally to POFs. In extreme cases, even negative $\alpha_{/ /}$can be expected. In addition, the experimental data acquired by Zhang and Webb [76] suggested $\alpha / /$ to be lower than the literature values of $\alpha_{\mathrm{sis}}$. This could explain the two orders of magnitude difference in $\alpha_{/ /}$obtained for the $3 \mathrm{D}$ PC $\mathrm{mPOF}$

\section{Fiber Bragg Grating Inscription and Testing}

\section{A. Inscription Using a Continuous-Wave Helium- Cadmium Laser}

A fiber Bragg grating (FBG1) was inscribed in the manufactured PC fiber by the phase mask technique [80] using a Kimmon $325 \mathrm{~nm}$ CW HeCd laser (model IK3301 R-G). The laser beam (power $\sim 23 \mathrm{~mW}$ and $\sim 1.2 \mathrm{~mm}$ diameter) was focused on the fiber through a cylindrical lens of $11 \mathrm{~cm}$ focal length. An Ibsen Photonics custom-made phase mask of $557.50 \mathrm{~nm}$ pitch was placed directly on the fiber. The inscription time was 13 min. FBG1 was inscribed $10-15 \mathrm{~mm}$ away from the butt-coupling fiber end in order to minimize losses of optical power due to fiber attenuation. After the inscription, FBG1 was interrogated through a $3 \mathrm{~dB}$ coupler using a supercontinuum light source Fianium White laser WLSC-400 and a Yokogawa AQ6373B optical spectrum analyzer. The reflection spectrum recorded by OSA is shown in Fig. 11. The calculated effective refractive index of the fiber core at the Bragg wavelength $\sim 871.8 \mathrm{~nm}$ is 1.5638 .

The response of FBG1 to temperature was tested. In order to facilitate grating interrogation, a silica pigtail was glued to the mPOF with FBG1. Some UV-curable glue (Norland Optical Adhesive 78) was placed in the junction point between silica and polymer fibers. They were positioned with respect to each other so that reflection spectrum was single mode, and then the UV glue was cured. However, after curing the glue, the reflection spectrum of FBG1 displayed two peaks rather than one due to change in light coupling conditions. As it was explained in Section III.-B, 1-1.5 cm distance between gluing point and the POFBG allowed higher order modes to propagate. Longer distance between fiber end and the FBG would increase the loss for higher order modes greatly and render them invisible.

FBG1 was subsequently placed in a small $\mathrm{v}$-groove on a Peltier plate and covered with some silicone grease to increase thermal conduction. The temperature was increased using a temperature electronic controller (TEC) from $27^{\circ} \mathrm{C}$ to $42^{\circ} \mathrm{C}$ in steps of $5^{\circ} \mathrm{C}$ in room environment. The recorded spectra are shown in Fig. 12, along with their moving averages serving to increase legibility of the plot. The temperature sensitivity was calculated from the moving averages by taking the central wavelength of $-3 \mathrm{~dB}$ bandwidth of either peak at different temperatures (see inset in Fig. 12). The calculated temperature sensitivity was around $-21.3 \pm 1.9 \mathrm{pm} /{ }^{\circ} \mathrm{C}\left(-21.2 \pm 1.9 \mathrm{pm} /{ }^{\circ} \mathrm{C}\right.$ for the left peak and $-21.4 \pm 1.0 \mathrm{pm} /{ }^{\circ} \mathrm{C}$ for the right one). This value was similar to the ones achieved in previous studies on PC mPOFs: $-25.8 \mathrm{pm} /{ }^{\circ} \mathrm{C}$ in a humidity-controlled environment [14] and $-29.9 \mathrm{pm} /{ }^{\circ} \mathrm{C}$ in a room environment [13]. Lack of humidity control does not seem to have major impact on achieved temperature sensitivity values, as the humidity sensitivity of FBG inscribed in PC mPOF is only $7.25 \mathrm{pm} / \% \mathrm{RH}$ (as opposed to $27.4-35.5 \mathrm{pm} / \% \mathrm{RH}$ for POFs made of PMMA $[26,81]$ ).

Knowing the temperature sensitivity of FBG1 $\left(\Delta \lambda_{\mathrm{B}} / \Delta T\right)$, the effective RI $\left(n_{f f}\right)$ of the fiber core at $\sim 871.8 \mathrm{~nm}\left(\lambda_{B}\right)$ and the LCTE of the fiber along fiber axis $\left(\alpha_{\| /)}\right.$allowed the thermo-optic coefficient perpendicular to fiber axis $\left(\mathrm{TOC}_{\perp},(d n / d T)_{\perp}\right)$ to be calculated. The fiber is not birefringent, so the TOC for all directions perpendicular to fiber axis is equal. COMSOL simulations showed that only up to $\sim 3.3 \%$ of electric field is parallel to fiber axis, the remainder being perpendicular to it Hence, it can be safely assumed that the Bragg peak position depends on $\mathrm{TOC}_{\perp}$ only. According to the equation describing Bragg wavelength change on temperature [75]:

$$
\frac{\Delta \lambda_{B}}{\lambda_{B}}=\left(\left.\frac{1}{n_{e f f}} \frac{\mathrm{d} n}{\mathrm{~d} T}\right|_{\perp}+\alpha_{\|}\right) \Delta T
$$

thermo-optic coefficient can be expressed as:

$$
\left.\frac{\mathrm{d} n}{\mathrm{~d} T}\right|_{\perp}=n_{e f f}\left(\frac{1}{\lambda_{B}} \frac{\Delta \lambda_{B}}{\Delta T}-\alpha_{\|}\right)
$$

Using the above equation, $\mathrm{TOC}_{\perp}$ was calculated to be $-39.4 \pm 3.7 \times 10^{\circ}{ }^{\circ} \mathrm{C}^{-1}$. The experimental error was estimated with the total differential method. It should be noted that the obtained $\mathrm{TOC}_{\perp}$ value is less than those found in the literature for $\mathrm{PC}$ in bulk and in the thin film form $\left(-90\right.$ to $-172 \times 10^{-6}{ }^{\circ} \mathrm{C}^{-1}$, most sources giving the value of about $\left.-107 \times 10^{-{ }^{\circ}} \mathrm{C}^{-1}\right)[65,66$, $67,68,69,82,83,84,85]$. Similarly to LCTE, this lower value of $\mathrm{TOC}_{\perp}$ can suggest that TOC is anisotropic, which would be justified in view of high anisotropy of molecular arrangement. However, further studies are required to fully understand fiber behavior.

\section{B. Inscription Using a Femtosecond Laser}

Another FBG (FBG2) was inscribed in the manufactured fiber by means of a femtosecond laser system (High Q Laser FemtoREGEN) operating at $517 \mathrm{~nm}$ with $220 \mathrm{fs}$ pulse duration. The fiber sample was fixed to a glass slide to minimize unwanted strain and bending and was subsequently mounted onto a 2D air-bearing translation system (Aerotech) for accurate motion control during inscription. The laser beam was focused 
on the fiber core by a long working distance objective $(\times 50$ Mitutoyo) using another translation stage. The laser pulse energy and repetition rate were set to $\sim 50 \mathrm{~nJ} /$ pulse and $1 \mathrm{kHz}$, respectively.

Using the plane-by-plane inscription method $[86,87,88]$, 1000 planes were inscribed in the fiber core with a period of $\sim 1.97 \mu \mathrm{m}$, giving a total grating length of $2 \mathrm{~mm}$ (see Fig. 13(a)).

The fiber was cleaved with a cold blade and butt-coupled to using silica fiber and refractive index matching gel. It was subsequently illuminated through a $3 \mathrm{~dB}$ coupler using a broadband light source (ASE730, Thorlabs, range 1530$1610 \mathrm{~nm}$ ). The reflection spectrum of the grating was measured using a commercial FBG interrogator (IBSEN IMON 512 HS), see Fig. 13(b). The effective refractive index of fiber core at $\sim 1562 \mathrm{~nm}$ (4" order FBG reflection) according to the resultant reflection spectrum was estimated to be $\sim 1.586$.

The operation of FBG2 was tested qualitatively. Fig. 14(a) shows the response of the grating to random vibrations of the optical table after hitting it three times. The response of the grating to three breath cycles is shown in Fig. 14(b). Here, the Bragg peak wavelength decreases with the increased temperature from each exhalation, yielding negative temperature sensitivity (in line with the results achieved in Section IV.-A)

\section{Inscription Using a Krypton-Fluoride Laser}

A Coherent Bragg Star Industrial-LN krypton fluoride $(\mathrm{KrF})$ excimer laser system operating at $248 \mathrm{~nm}$ wavelength was employed to inscribe the third FBG introduced in the paper (FBG3). The pulse duration and pulse repetition rate were $15 \mathrm{~ns}$ and $1 \mathrm{~Hz}$, respectively. The laser beam profile was measured as a rectangular Tophat function of $6.0 \times 1.5 \mathrm{~mm}^{2}$ size and $2 \times 1 \mathrm{mrad}^{2}$ divergence. It was focused onto the fiber core utilizing a plano-convex cylindrical lens (Newport CSX200AR.10) with the focal length of $20 \mathrm{~cm}$. The effective spot size of the beam on the fiber surface was $20.0 \mathrm{~mm}$ in width and $32.4 \mu \mathrm{m}$ in height. A slit perpendicular to the fiber direction is used to reduce the width of the beam, which defines the physical length of the grating structure (in this case $5 \mathrm{~mm}$ long). A $10 \mathrm{~mm}$ long phase mask customized for $248 \mathrm{~nm}$ inscription wavelength with a pitch of $567.8 \mathrm{~nm}$ was used for Bragg grating inscription at the $850 \mathrm{~nm}$ spectral region. A supercontinuum source (Fianium White laser WL-SC-400) and an optical spectrum analyzer (Yokogawa AQ6373B) were used to measure power reflected from the grating through a $3 \mathrm{~dB}$ coupler.

Due to high fiber attenuation at this wavelength short fiber sections of around $4 \mathrm{~cm}$ were used. They were butt-coupled to an APC silica pigtail and a small amount of index gel was inserted to reduce Fresnel reflections. It took $5 \mathrm{~min}$ to inscribe a grating ( 300 pulses at $1 \mathrm{~Hz}$ pulse repetition rate, $0.6 \mathrm{~mJ}$ energy per pulse). The resulting FBG was $5 \mathrm{~mm}$ long and its Bragg wavelength was $887.25 \mathrm{~nm}$ (see Fig. 15). From the Bragg peak the effective refractive index at that wavelength was calculated to be 1.5626 , which is very close to this calculated in Section IV .-A (1.5638 at $~ 871.8 \mathrm{~nm})$ and in [13].

\section{CONCLUSIONS}

This paper reports the first single-mode microstructured solid-core fiber drawn from a 3D-printed preform. The fiber preform was printed in a standard lab with a commercial, lowcost printer. Whilst the preform fabrication process is not optimal in terms of the optical transparency of the fiber produced at this stage, it guides light over a sufficient distance to show the successful inscription of fiber Bragg gratings using three different laser systems: a $325 \mathrm{~nm} \mathrm{CW}$ laser, a $517 \mathrm{~nm}$ pulsed femtosecond laser and a $248 \mathrm{~nm}$ pulsed nanosecond laser. The reflection peaks of these gratings were in the 850$900 \mathrm{~nm}$ and $1550-1600 \mathrm{~nm}$ regions, showing light guiding over a wide wavelength range.

Mechanical testing of the fiber showed that the 3D printing approach did not introduce any unexpected or undesirable characteristics. The fiber attenuation was the lowest reported so far for a POF drawn from a 3D-printed preform and the fiber was shown to operate in the $1550 \mathrm{~nm}$ region, which is useful for using with existing test and measurement equipment. The measured linear coefficient of thermal expansion was found to be two orders of magnitude smaller than for isotropic bulk material. Thermo-optic coefficient of the fiber was calculated to be only $\sim 37 \%$ of this for isotropic bulk PC. Both of these are ascribed to high anisotropy of molecular arrangement in the 3D $\mathrm{PC} \mathrm{mPOF}$, but further studies are necessary to fully understand fiber behavior.

Whilst the current performance is not yet as good as that of fibers drawn from preforms made by drilling or capillary stacking, the ultimate aim of this work is to optimize a technique that will facilitate complex fiber designs that cannot be easily fabricated with the conventional techniques. It is reasonable to expect that printing with tailor-made filaments rather than commercially available ones would allow much better control of the printing process. The custom-made filaments could be fabricated of optical quality plastics, which could result in decreasing the loss levels. In addition, their chemical composition could be precisely controlled, which could allow avoiding undesired chemical species that can adversely interfere with the POF fabrication process.

\section{REFERENCES}

[1] S. H. Huang, P. Liu, A. Mokasdar, and L. Hou, "Additive manufacturing and its societal impact: A literature review," (in English), International Journal of Advanced Manufacturing Technology, Review vol. 67, no. 5-8, pp. 1191-1203, 2013

[2] T. J. Horn and O. L. A. Harrysson, "Overview of current additive manufacturing technologies and selected applications," (in English), Science Progress, Article vol. 95, no. 3, pp. 255-282, 2012.

[3] K. Cook et al., "Step-index optical fiber drawn from 3D printed preforms," (in English), Optics Letters, vol. 41, no. 19, pp. 4554-4557, Oct 12016.

[4] Q. K. Zhao et al., "Optical fibers with special shaped cores drawn from 3D printed preforms," (in English), Optik, vol. 133, pp. 60-65, 2017.

[5] K. Cook et al., "Air-structured optical fiber drawn from a 3Dprinted preform," Opt Lett, vol. 40, no. 17, pp. 3966-9, Sep 1 2015

[6] M. G. Zubel, A. Fasano, G. Woyessa, K. Sugden, H. K. Rasmussen, and O. Bang, "3D-printed PMMA preform for hollow-core POF drawing," presented at the 25th International Conference on Plastic Optical Fibres, POF 2016, Birmingham, United Kingdom, 2017. Conference Paper. Available: https://www.scopus.com/inward/record.uri?eid=2-s2.0- 
85021399589\&partnerID $=40 \& m d 5=3 \mathrm{~d} 3 \mathrm{df} 47198 \mathrm{~b} 277 \mathrm{f} 4 \mathrm{~b} 69$ $254796167947 \mathrm{~b}$

[7] T. H. R. Marques, B. M. Lima, J. H. Osorio, L. E. da Silva, and C. M. B. Cordeiro, "3D Printed Microstructured Optical Fibers," presented at the 2017 SBMO/IEEE MTT-S International Microwave and Optoelectronics Conference (Imoc), 2017. Available: $<$ Go to ISI >://WOS:000419280400078

[8] W. Talataisong et al., "Mid-IR Hollow-core microstructured fiber drawn from a 3D printed PETG preform," (in English), Scientific Reports, vol. 8, May 252018.

[9] J. Canning, M. A. Hossain, C. Y. Han, L. Chartier, K. Cook, and T. Athanaze, "Drawing optical fibers from threedimensional printers," (in English), Optics Letters, vol. 41, no. 23, pp. 5551-5554, Dec 12016.

[10] $\mathrm{S}$. Li et al., "A $0.1 \mathrm{THz}$ low-loss 3D printed hollow waveguide," Optik, vol. 176, pp. 611-616, 2019/01/01/2019.

[11] S. Pandey, B. Gupta, and A. Nahata, "Terahertz plasmonic waveguides created via 3D printing," Optics Express, vol. 21, no. 21, pp. 24422-24430, 2013/10/21 2013

[12] A. L. S. Cruz, C. M. B. Cordeiro, and M. A. R. Franco, "3D Printed Hollow-Core Terahertz Fibers," Fibers, vol. 6, no. 3, p. 43, 2018.

[13] A. Fasano et al., "Fabrication and characterization of polycarbonate microstructured polymer optical fibers for high-temperature-resistant fiber Bragg grating strain sensors," (in English), Optical Materials Express, vol. 6, no. 2, pp. 649-659, Feb 12016.

[14] G. Woyessa, A. Fasano, C. Markos, H. K. Rasmussen, and O. Bang, "Low Loss Polycarbonate Polymer Optical Fiber for High Temperature FBG Humidity Sensing," (in English), IEEE Photonics Technology Letters, vol. 29, no. 7, pp. 575578, Apr 12017

[15] C. Markos, A. Stefani, K. Nielsen, H. K. Rasmussen, W. Yuan, and O. Bang, "High-T-g TOPAS microstructured polymer optical fiber for fiber Bragg grating strain sensing at 110 degrees," Optics Express, vol. 21, no. 4, pp. 4758-4765, 2013.

[16] G. Woyessa, A. Fasano, C. Markos, A. Stefani, H. K. Rasmussen, and O. Bang, "Zeonex microstructured polymer optical fiber: fabrication friendly fibers for high temperature and humidity insensitive Bragg grating sensing," (in English), Optical Materials Express, vol. 7, no. 1, pp. 286295, Jan 12017.

[17] K. E. Carroll, C. Zhang, D. J. Webb, K. Kalli, A. Argyros, and $\mathrm{M}$. C. Large, "Thermal response of Bragg gratings in PMMA microstructured optical fibers.," Optics express, vol. 15, no. 14, pp. 8844-50, 2007.

[18] D. Celentano, D. Wimmer, L. Colabella, and A. P. Cisilino, "Viscoelastic mechanical characterization of a short-fiber reinforced polyethylene tube: Experiments and modelling," (in English), International Journal of Pressure Vessels and Piping, vol. 134, pp. 82-91, Oct 2015.

[19] S. Ropers, M. Kardos, and T. A. Osswald, "A thermoviscoelastic approach for the characterization and modeling of the bending behavior of thermoplastic composites," (in English), Composites Part a-Applied Science and Manufacturing, vol. 90, pp. 22-32, Nov 2016.

[20] T. C. Henry, C. E. Bakis, and E. C. Smith, "Viscoelastic characterization and self-heating behavior of laminated fiber composite driveshafts," (in English), Materials \& Design, vol. 66, pp. 346-355, Feb 52015.

[21] I. K. Lin, K. S. Ou, Y. M. Liao, Y. Liu, K. S. Chen, and X. Zhang, "Viscoelastic Characterization and Modeling of Polymer Transducers for Biological Applications," (in English), Journal of Microelectromechanical Systems, vol. 18, no. 5, pp. 1087-1099, Oct 2009.

[22] A. Stefani, S. Andresen, W. Yuan, and O. Bang, "Dynamic Characterization of Polymer Optical Fibers," (in English), IEEE Sensors Journal, vol. 12, no. 10, pp. 3047-3053, Oct 2012.

[23] A. G. Leal, C. Marques, A. Frizera, and M. J. Pontes, "Dynamic Mechanical Analysis on a PolyMethyl Methacrylate (PMMA) Polymer Optical Fiber," (in English), IEEE Sensors Journal, vol. 18, no. 6, pp. 2353-2361, Mar 15 2018.
[24] A. Leal et al., "Dynamic mechanical characterization with respect to temperature, humidity, frequency and strain in mPOFs made of different materials," (in English), Optical Materials Express, vol. 8, no. 4, pp. 804-815, Apr 12018.

[25] A. Leal et al., "Dynamic mechanical analysis on fused polymer optical fibers: towards sensor applications," (in English), Optics Letters, vol. 43, no. 8, pp. 1754-1757, Apr 152018 .

[26] D. J. Webb, "Polymer Fibre Bragg Grating Sensors and their Applications," in Optical Fiber Sensors: Advanced Techniques and Applications, G. Rajan, Ed. United Kingdom: CRC Press, 2015, p. 576.

[27] M. G. Zubel, K. Sugden, D. Saez-Rodriguez, K. Nielsen, and O. Bang, "3-D printed sensing patches with embedded polymer optical fibre Bragg gratings," presented at the Sixth European Workshop on Optical Fibre Sensors (EWOFS'2016), Limerick, Ireland, 2016. Available: $<$ Go to ISI>://WOS:000378434400085 https://www.spiedigitallibrary.org/conference-proceedingsof-spie/9916/99162E/3D-printed-sensing-patches-withembedded-polymer-optical-fibreBragg/10.1117/12.2237495.pdf

[28] M. G. Zubel, K. Sugden, D. J. Webb, D. Saez-Rodriguez, K Nielsen, and O. Bang, "Embedding silica and polymer fibre Bragg gratings (FBG) in plastic 3D-printed sensing patches," presented at the Micro-Structured and Specialty Optical Fibres IV, SPIE Photonics Europe 2016, Brussels, Belgium, 2016. Available: $<$ Go to ISI $>$ ://WOS:000389681800014 https://www.spiedigitallibrary.org/conference-proceedingsof-spie/9886/98860N/Embedding-silica-and-polymer-fibreBragg-gratings-FBG-in-plastic/10.1117/12.2228753.pdf

[29] A. Pospori et al., "Annealing effects on strain and stress sensitivity of polymer optical fibre based sensors," presented at the Micro-Structured and Specialty Optical Fibres IV, SPIE Photonics Europe 2016, Brussels, Belgium, 2016. Available: $<$ Go to ISI $>$ ://WOS:000389681800020 https://www.spiedigitallibrary.org/conference-proceedingsof-spie/9886/98860V/Annealing-effects-on-strain-andstress-sensitivity-of-polymeroptical/10.1117/12.2227473.pdf

[30] A. Lacraz et al., "Embedding low loss polymer optical fibre Bragg gratings: Two different approaches," presented at the 25th International Conference on Plastic Optical Fibres, POF 2016, Birmingham, United Kingdom, 2017. Conference Paper. Available: https://www.scopus.com/inward/record.uri?eid=2-s2.085021440609 \& partnerID=40\&md5=f0aad307554b0e511be $3674 \mathrm{~b} 62019 \mathrm{~d} 16$

[31] F. Berghmans et al., "Photonic skins for optical sensing: Highlights of the PHOSFOS Project," presented at the 20th International Conference on Optical Fibre Sensors, Edinburgh, United Kingdom, 2009. Available: http://www.scopus.com/inward/record.url?eid=2-s2.070449389816\&partnerID=40\&md5=37a5766e0f9db559b31 add0c51cec37d http://proceedings.spiedigitallibrary.org/data/Conferences/S PIEP/10273/75030B_1.pdf

[32] X. Chen et al., "Polymer photonic sensing skin," presented at the 4th European Workshop on Optical Fibre Sensors, Porto, Portugal, $2010 . \quad$ Available: http://www.scopus.com/inward/record.url?eid=2-s2.0$77957832408 \&$ partnerID $=40 \& \mathrm{md} 5=\mathrm{e} 2 \mathrm{e} 575568 \mathrm{fb} 14 \mathrm{~b} 113 \mathrm{~d} 1$ $588 \mathrm{ad} 32 \mathrm{c} 3 \mathrm{bdfa}$ http://proceedings.spiedigitallibrary.org/data/Conferences/S PIEP/7543/76533A 1.pdf

[33] Y. Mizuno, R. Ishikawa, H. Lee, A. Theodosiou, K. Kalli, and K. Nakamura, "Potential of discriminative sensing of strain and temperature using perfluorinated polymer FBG," IEEE Sensors Journal, pp. 1-1, 2019

[34] G. Woyessa et al., "Zeonex-PMMA microstructured polymer optical FBGs for simultaneous humidity and temperature sensing," (in English), Optics Letters, vol. 42, no. 6, pp. 1161-1164, Mar 152017.

[35] G. Woyessa, K. Nielsen, A. Stefani, C. Markos, and O. Bang, "Temperature insensitive hysteresis free highly sensitive 
polymer optical fiber Bragg grating humidity sensor," Optics Express, vol. 24, no. 2, pp. 1206-1213, 2016/01/25 2016.

[36] A. Pospori, C. A. F. Marques, D. Saez-Rodriguez, K. Nielsen, O. Bang, and D. J. Webb, "Sensitivity enhancement using annealed polymer optical fibre based sensors for pressure sensing applications," presented at the Sixth European Workshop on Optical Fibre Sensors (EWOFS'2016), Limerick, Ireland, 2016. Available: $<$ Go to ISI $>$ ://WOS:000378434400013

https://www.spiedigitallibrary.org/conference-proceedingsof-spie/9916/99160E/Sensitivity-enhancement-usingannealed-polymer-optical-fibre-based-sensorsfor/10.1117/12.2236877.pdf

[37] R. Ishikawa et al., "Pressure Dependence of Fiber Bragg Grating Inscribed in Perfluorinated Polymer Fiber," IEEE Photonics Technology Letters, vol. 29, no. 24, pp. $2167-$ 2170, 2017.

[38] W. Zhang, D. Webb, and G. Peng, "Polymer optical fiber Bragg grating acting as an intrinsic biochemical concentration sensor," (in English), Optics Letters, vol. 37, no. 8, pp. 1370-1372, 2012.

[39] A. Stefani, S. Andresen, W. Yuan, N. Herholdt-Rasmussen, and O. Bang, "High Sensitivity Polymer Optical FiberBragg-Grating-Based Accelerometer," (in English), IEEE Photonics Technology Letters, vol. 24, no. 9, pp. 763-765, May 12012.

[40] G. Woyessa et al., "Single mode step-index polymer optical fiber for humidity insensitive high temperature fiber Bragg grating sensors," (in English), Optics Express, vol. 24, no. 2, pp. 1253-1260, Jan 252016.

[41] C. A. F. Marques, A. Pospori, and D. J. Webb, "Timedependent variation of POF Bragg grating reflectivity and wavelength submerged in different liquids," (in English), Optics and Laser Technology, vol. 94, pp. 234-239, Sep 1 2017.

[42] C. Broadway et al., "A Compact Polymer Optical Fibre Ultrasound Detector," presented at the Photons Plus Ultrasound: Imaging and Sensing 2016, SPIE BiOS, , San Francisco, California, United States, 2016. Available: $<$ Go to ISI >://WOS:000378437000036 https://www.spiedigitallibrary.org/conference-proceedingsof-spie/9708/970813/A-compact-polymer-optical-fibreultrasound-detector/10.1117/12.2212420.pdf

[43] C. Broadway et al., "Microstructured polymer optical fibre sensors for opto-acoustic endoscopy," presented at the Micro-Structured and Specialty Optical Fibres IV, SPIE Photonics Europe 2016, Brussels, Belgium, 2016. Available $<$ Go to ISI $>$ ://WOS:000389681800018

https://www.spiedigitallibrary.org/conference-proceedingsof-spie/9886/98860S/Microstructured-polymer-opticalfibre-sensors-for-opto-acousticendoscopy/10.1117/12.2227588.pdf

[44] C. Broadway et al., "L-band CYTOP Bragg gratings for ultrasound sensing," presented at the Micro-Structured and Specialty Optical Fibres V, SPIE Photonics Europe, Strasbourg, France, 2018.

[45] W. Zhang and D. J. Webb, "Polymer optical fiber grating as water activity sensor," in Micro-Structured and Specialty Optical Fibres III, SPIE Photonics Europe, Brussels, Belgium, 2014, vol. 9128: SPIE

[46] C. A. F. Marques, G. D. Peng, and D. J. Webb, "Highly sensitive liquid level monitoring system utilizing polymer fiber Bragg gratings," (in English), Optics Express, vol. 23, no. 5, pp. 6058-6072, Mar 92015.

[47] P. Stajanca and K. Krebber, "Radiation-Induced Attenuation of Perfluorinated Polymer Optical Fibers for Radiation Monitoring," (in English), Sensors, vol. 17, no. 9, Sep 2017.

[48] C. C. Ye et al., "Applications of polymer optical fibre grating sensors to condition monitoring of textiles," in 20th International Conference on Optical Fibre Sensors, Edinburgh, 2009, vol. 7503

[49] M. C. J. Large, L. Poladian, G. W. Barton, and M. A. Van Eijkelenborg, Microstructured polymer optical fibres. Springer US, 2008

[50] A. Stefani, K. Nielsen, H. K. Rasmussen, and O. Bang, "Cleaving of TOPAS and PMMA microstructured polymer optical fibers: Core-shift and statistical quality optimization,"
Optics Communications, vol. 285, no. 7, pp. 1825-1833, 2012/04/01/2012.

[51] B. T. Kuhlmey, R. C. McPhedran, and C. M. de Sterke, "Modal cutoff in microstructured optical fibers," Optics Letters, vol. 27, no. 19, pp. 1684-1686, 2002/10/01 2002.

[52] F. Zolla et al., Foundations of Photonic Crystal Fibres. IMPERIAL COLLEGE PRESS, 2011, p. 552.

[53] "COMSOL v. 4.3," 4.3 ed. www.comsol.com: COMSOL $\mathrm{AB}$, Stockholm, Sweden.

[54] T. P. White et al., "Multipole method for microstructured optical fibers. I. Formulation," Journal of the Optical Society of America B, vol. 19, no. 10, pp. 2322-2330, 2002/10/01 2002.

[55] B. T. Kuhlmey et al., "Multipole method for microstructured optical fibers. II. Implementation and results," Journal of the Optical Society of America B, vol. 19, no. 10, pp. 2331-2340, 2002/10/01 2002

[56] B. T. Kuhlmey, "CUDOS MOF Utilities v. 2.1," Fibre 2.1.2.2 WinField 2.126 http://www.physics.usyd.edu.au/cudos/mofsoftware/index.h tml.

[57] P. McIsaac, "Symmetry-Induced Modal Characteristics of Uniform Waveguides - I: Summary of Results," IEEE Transactions on Microwave Theory and Techniques, vol. 23, no. 5 , pp. $421-429,1975$.

[58] R. Syms and J. Cozens, Optical Guided Waves and Devices London, United Kingdom: McGraw-Hill Education Europe, 1992, p. 500

[59] (2003, 11 Jul 2018). Materials Data Book. Available: http://wwwmdp.eng.cam.ac.uk/web/library/enginfo/cueddatabooks/mat erials.pdf

[60] H. K. Rasmussen, A. Fasano, P. Stajanca, G. Woyessa, M. Schukar, and O. Bang, "Mechanical characterization of drawn Zeonex, Topas, polycarbonate and PMMA microstructured polymer optical fibres," Optical Materials Express, vol. 8, no. 11, pp. 3600-3614, 2018/11/01 2018.

[61] R. M. Waxler, D. Horowitz, and A. Feldman, "Optical and physical parameters of Plexiglas 55 and Lexan," Applied Optics, vol. 18, no. 1, pp. 101-104, 1979/01/01 1979.

[62] Z. Zhang, P. Zhao, P. Lin, and F. Sun, "Thermo-optic coefficients of polymers for optical waveguide applications," Polymer, vol. 47, no. 14, pp. 4893-4896, 2006/06/28/ 2006.

[63] P. A. Soave, R. A. F. Dau, M. R. Becker, M. B. Pereira, and F. Horowitz, "Refractive index control in bicomponent polymer films for integrated thermo-optical applications," Optical Engineering, vol. 48, no. 12, pp. 1-6, 2009.

[64] M. R. Saleem, S. Honkanen, and J. Turunen, "Thermo-optic coefficient of Ormocomp and comparison of polymer materials in athermal replicated subwavelength resonant waveguide gratings," Optics Communications, vol. 288, pp. $56-65,2013 / 02 / 01 / 2013$

[65] G. Khanarian, "Optical properties of cyclic olefin copolymers," Optical Engineering, vol. 40, no. 6, pp. 10241029, 2001.

[66] Y. Sato, Y. Yamasaki, S. Takishima, and H. Masuoka, "Precise measurement of the PVT of polypropylene and polycarbonate up to $330^{\circ} \mathrm{C}$ and $200 \mathrm{MPa}, "$ Journal of Applied Polymer Science, vol. 66, no. 1, pp. 141-150, 1997.

[67] (4 Apr 2019). MATWEB: Overview of materials for Polycarbonate, Extruded. Available: http://matweb.com/search/DataSheet.aspx?MatGUID=501a cbb63cbc4f748faa7490884cdbca

[68] W. Yuan et al., "Humidity insensitive TOPAS polymer fiber Bragg grating sensor," Optics Express, vol. 19, no. 20, pp. 19731-19739, 2011/09/26 2011.

[69] X. Cheng et al., "High-sensitivity temperature sensor based on Bragg grating in BDK-doped photosensitive polymer optical fiber," Chinese Optics Letters, vol. 9, no. 2, p. 020602, 2011/02/10 2011 .

[70] G.-D. Peng and P. L. Chu, "Polymer optical fiber sensing," presented at the Optical Information Processing Technology, Photonics Asia, Shanghai, China, 2002. Available: https://doi.org/10.1117/12.483228

[71] A. Bar-Cohen, B. Han, and K. Joon Kim, "Thermo-Optic Effects in Polymer Bragg Gratings," in Micro- and OptoElectronic Materials and Structures: Physics, Mechanics, 
Design, Reliability, Packaging, E. Suhir, Y. C. Lee, and C. P. Wong, Eds. Boston, MA: Springer US, 2007, pp. A65-A110.

[72] W. Zhang and D. J. Webb, "Factors influencing the temperature sensitivity of PMMA based optical fiber Bragg gratings," presented at the Micro-structured and Specialty Optical Fibres III, SPIE Photonics Europe, Brussels, Belgium, 2014.2 Available: https://doi.org/10.1117/12.2054210

[73] I. M. Ward, "The preparation, structure and properties of ultra-high modulus flexible polymers," Advances in Polymer Science, pp. 1-70, 1985.

[74] V. B. Gupta, "Nature of the Crystalline and Amorphous Phases in Oriented Polymers and Their Influence on Physical Properties," in Oriented Polymer Materials, S. Fakirov, Ed. WILEY-VCH Verlag, 2008.

[75] R. Schledjewski and K. Friedrich, "Orientation Effects on the Thermal, Mechanical and Tribological Performance of Neat, Reinforced and Blended Liquid Crystalline Polymers," in Oriented Polymer Materials, S. Fakirov, Ed.: WILEY-VCH Verlag, 2008

[76] H. Dobb, D. J. Webb, K. Kalli, A. Argyros, M. C. J. Large, and M. a. van Eijkelenborg. "Continuous wave ultraviolet light-induced fiber Bragg gratings in few- and single-mode microstructured polymer optical fibers," Optics letters, vol. 30 , no. 24 , pp. $3296-8,2005$

[77] G. Woyessa, "Speciality and microstructured polymer optical FBG sensors," PhD Ph.D. thesis, Technical University of Denmark, Copenhagen, Denmark, 2017

[78] A. Rosenberg, S. H. Lee, J. S. Shirk, and G. Beadie, "Optothermal characteristics of amorphous polyimides for optical applications," Optical Materials Express, vol. 8, no. 8, pp. 2159-2172, 2018/08/01 2018

[79] J. M. Cariou, J. Dugas, L. Martin, and P. Michel, "Refractiveindex variations with temperature of PMMA and polycarbonate," Applied Optics, vol. 25, no. 3, pp. 334-336, 1986/02/01 1986

[80] R. S. Moshrefzadeh, M. D. Radcliffe, T. C. Lee, and S. K. Mohapatra, "Temperature dependence of index of refraction of polymeric waveguides," Journal of Lightwave Technology, vol. 10, no. 4, pp. 420-425, 1992.

[81] J.-g. Chen et al., "Low-loss planar optical waveguides fabricated from polycarbonate," Polymer Engineering \& Science, vol. 49, no. 10, pp. 2015-2019, 2009/10/01 2009

[82] A. Theodosiou, A. Lacraz, A. Stassis, C. Koutsides, M. Komodromos, and K. Kalli, "Plane-by-Plane Femtosecond Laser Inscription Method for Single-Peak Bragg Gratings in Multimode CYTOP Polymer Optical Fiber," (in English), Journal of Lightwave Technology, vol. 35, no. 24, pp. 54045410 , Dec 152017

[83] A. Theodosiou, X. H. Hu, C. Caucheteur, and K. Kalli, "Bragg Gratings and Fabry-Perot Cavities in Low-Loss Multimode CYTOP Polymer Fiber," (in English), IEEE Photonics Technology Letters, vol. 30, no. 9, pp. 857-860, May 12018

[84] A. Ioannou, A. Theodosiou, C. Caucheteur, and K. Kalli, "Direct writing of plane-by-plane tilted fiber Bragg gratings using a femtosecond laser," (in English), Optics Letters, vol. 42, no. 24, pp. 5198-5201, Dec 152017 .

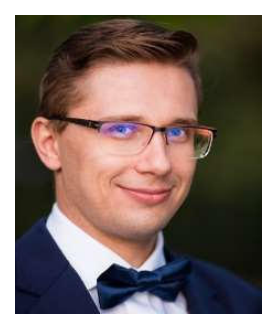

Michal G. Zubel received his BEng degree in electronics from Wroclaw University of Technology in 2012. He studied at Ecole Normale Supérieure de Cachan, France, Universidad Complutense de Madrid, Spain and Wroclaw University of Technology, Poland, in the framework of Erasmus Mundus "Monabiphot" Master programme. In 2014, he joined Aston University as a PhD student and a Marie Curie Early Stage Researcher within the Marie Curie Actions Innovative Training Network project TRIPOD aiming at advancing the technology of polymer optical fibers. He is due to graduate in early 2020 with a PhD in applied physics. Current research interests entail design and fabrication of polymer optical fibers, fiber Bragg gratings, and $3 \mathrm{D}$ printing.

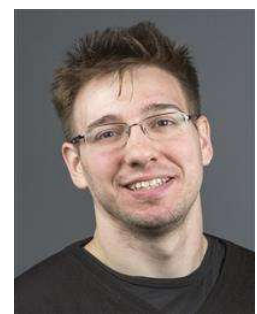

Andrea Fasano holds a B.Sc. degree in Chemical Engineering, an M.Sc. degree in Process and Materials Engineering from University of Trieste, Italy, and a Ph.D. in Mechanical Engineering from Technical University of Denmark (DTU). He received his Ph.D. degree in 2017 as part of the Marie Curie Initial Training Network project TRIPOD at DTU Mekanik, Department of Mechanical Engineering. Further work experience includes a postdoc at DTU Kemiteknik, Department of Chemical and Biochemical Engineering and several R\&D engineering projects in industry. Research interests encompass materials science, non-Newtonian fluid mechanics, optical fibers, sensors, coating science, micro/nanotechnology, medical devices and digital health.

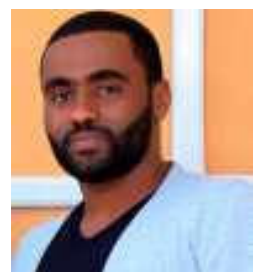

Getinet Woyessa Getinet Taffesse Woyessa was born in Addis Ababa, Ethiopia, in 1987. He received a B.Sc. degree in Electrical Engineering from Haramaya University, Ethiopia, in 2008. He holds an Erasmus Mundus Joint Master's degree in Photonic Network Engineering (MAPNET) from Scuola Superiore Sant'Anna and Aston University (2013). He joined the Fibre Sensors and Supercontinuum group, Department of Photonics Engineering, Technical University of Denmark (DTU) in 2014 and received his $\mathrm{PhD}$ degree in Photonics Engineering from the as part of the Marie Curie ITN project TRIPOD in 2017. From 2017-2019 he was a postdoctoral researcher on mid infrared pulsed laser and long wavelength supercontinuum generation under the H2020 FLAIR project. Currently, he is a research scientist with main focus on fabrication of specialty optical fibers, optical fiber materials, supercontinuum sources, fiber lasers, fiber sensors technologies and their applications.

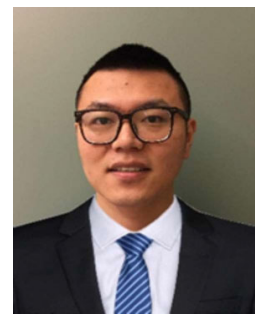

Rui Min was born in Anhui, China, in 1989. He received a B.Sc. Degree from Wuhan University of Technology in 2010, M.Sc. degree from Harbin Engineering University in 2015 , and $\mathrm{PhD}$ degree from Universidad Politécnica de Valencia in 2019. He has published more than 30 papers and conference contributions in polymer fiber fiber sensors and microwave photonics. Now his research is focused on polymer fiber grating for communications and microwave photonics.

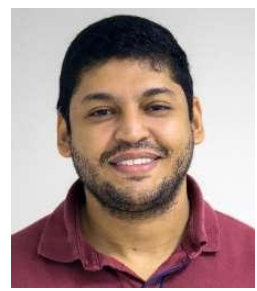

Arnaldo G. Leal-Junior was born in Uberlandia Brazil, in 1991. He received the B.S. degree in mechanical engineering and the Ph.D. degree in electrical engineering from the Universidade Federal do Espírito Santo (UFES), Brazil, in 2015 and 2018, respectively. He is currently a professor in the mechanical engineering Department, UFES. He has authored or coauthored more than 90 papers in scientific journals, books and conferences in the fields of mechanical, electrical and biomedical engineering. His research interests include optical fiber sensors with emphasis on polymer optical fiber sensors, robotic systems, instrumentation and actuators.

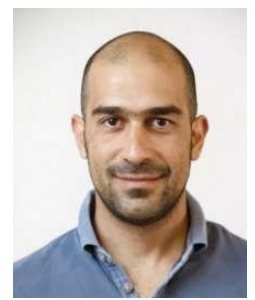

Antreas Theodosiou received his B.Sc. in 2011 and his M.Sc. in 2013 in electrical engineering communication systems and his Ph.D. in 2018 from Cyprus University of Technology. His main research objectives focused on the development of optical fiber sensors using femtosecond laser inscription in polymer optical fiber (POF), silicabased fibers, and other new materials such as Silicon fibers. In parallel, he worked with the design of demodulation algorithms for complicated and multimode Bragg gratings using signal processing techniques. Moreover, he is interested in the development of monolithic 
NIR and MIR continues-wave and mode-locked fiber lasers. He published more than 30 papers in high impact factor journals and participates in various European and Cyprus funded research projects.

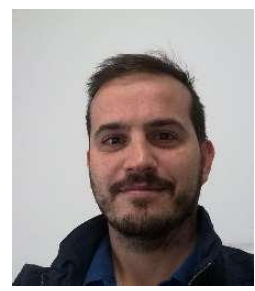

Carlos A.F. Marques received the Master and Ph.D. degrees in Physics Engineering from the University of Aveiro (UA), Portugal, in 2008 and 2013, respectively. He was a Marie Curie Fellow in the Aston Institute of Photonic Technologies, Aston University, UK from 2014 to 2016 Currently, he is a Senior Researcher at Physics Department \& I3N, UA, Portugal. His main interests include optical fiber devices for sensing, data acquisition and processing and optical transmission data. $\mathrm{He}$ authored or co-authored $200+$ journal/conference papers and 1 prototype with emphasis on optical communications and sensing. He has participated in 18+ national and European research projects.

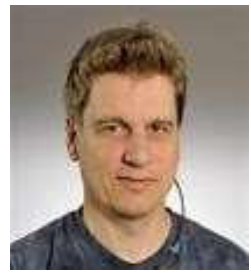

Henrik K Rasmussen is Associate Professor, in the Department of Mechanical Engineering at the Technical University of Denmark (DTU).

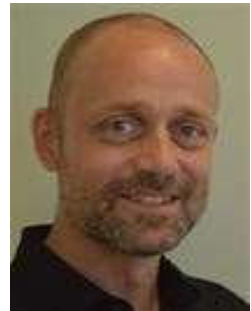

Ole Bang received an M.Sc. degree in electrica engineering and Ph.D. degree in nonlinear physics from the Technical University of Denmark (DTU), Kongens Lyngby, Denmark, in 1992 and 1993, respectively. In 1993-1995, he was a postdoc with the Laboratoire de Physique, Ecole Normale Superieure de Lyon, France, working on discrete physical models of the nonlinear dynamics of biomolecules. From 1995-1999, he was a Research Fellow with the Optical Sciences Centre, Australian National University, Canberra, Australia, where he worked theoretically on nonlinear optics, in particular, on solitons and modulational instability in materials with a quadratic nonlinearity and quasiphase-matching gratings. In 1999-2003, he was an Associate Professor with the Department of Informatics and Mathematical Modeling, DTU. Since 2003, he has been with DTU Fotonik, Department of Photonics Engineering, DTU, where he became a Professor in 2011 and is now heading the Fiber Sensors and Supercontinuum Group. His current research interests include microstructured optical fibers in silica, polymer and soft glasses, fiber optical sensors for sensing biomolecules, $\mathrm{pH}$, oxygen, humidity, stress/strain, in particular using Fibre Bragg gratings, as well as the fabrication and application of supercontinuum sources, in particular in imaging, such as OCT and photoacoustic imaging. He is a Fellow of the Optical Society of America.

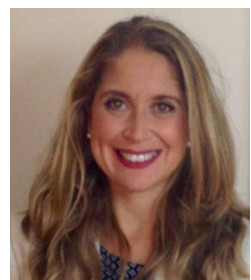

Beatriz Ortega (was born in Valencia, Spain, in 1972. She received the M.Sc. degree in Physics in 1995 from the Universidad de Valencia, and the Ph.D. in Telecommunications Engineering in 1999 from the Universidad Politécnica de Valencia. Currently working at the Departamento de Comunicaciones from the Universitat Politècnica de València and collaborating as a group leader in the Photonics Research Labs in the Institute of Telecommunications and Multimedia Applications. She has published more than 200 papers and conference contributions in fibre Bragg gratings, microwave photonics and optical networks. She has got several patents and is also a co-founder of EPHOOX company. She has participated in a large number of European Networks of Excellence and $R \& D$ projects and other national ones. Her main research is currently focused on optical devices, optical networks and microwave photonic systems and applications.

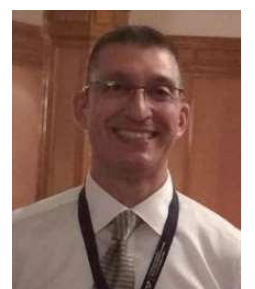

Kyriacos Kalli (C.Phys. MIEEE, SMOSA) received a B.Sc. in theoretical physics (1988) and Ph.D. in physics (1992) from the University of Kent, UK, where he studied linear and non-linear phenomena in optical fibers. He joined Cyprus University of Technology (CUT) in 2008 and is a Professor in the Department of Electrical Engineering, Computer Engineering and Informatics; he is also Director of the Photonics and Optical Sensors Research Laboratory and runs the Femtosecond Laser Foundry. He has $230+$ journal and conference publications, is coauthor of "Fiber Bragg Gratings: Fundamentals and Applications in Telecommunications and Sensing. His research interests are in Bragg grating and optical fiber sensors, femtosecond laser micro-fabrication of photonic devices, microfluidics and plasmonics. Dr. Kalli is currently on the Board of Directors of the Cyprus Organization for Standardization.

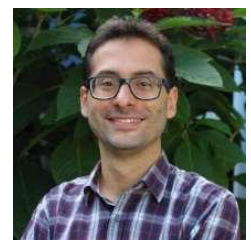

Anselmo Frizera Graduated in Electrical Engineering from the Federal University of Espirito Santo (2006) and Ph.D. in Electronics from the University of Alcalá (Spain, 2010). 20062010 he was a researcher of the Bioengineering Group of Consejo Superior de Investigaciones Científicas (CSIC, Spain). In 2010 he became a Professor of the Department of Electrical Engineering, and in 2011 a Permanent Professor of the Post-Graduate Program in Electrical Engineering, both at the Federal University of Espirito Santo (UFES). He is the Coordinator of the Laboratory of Telecommunications (LabTel) of UFES and a member of the Board of Directors of the Ibero-American Association of Disability Support Technologies (AITADIS) 2014-2018, contributing to the diffusion of knowledge in the area of technologies to support the countries of Latin America and the Iberian Peninsula. Prof. Frizera has experience in Electronics, Photonics and Biomedical Engineering. His research interests and areas of expertise are rehabilitation robotics, development of optical and electronic sensors for human-machine interfaces, biomedical signal processing, disability and mobility aids technologies.

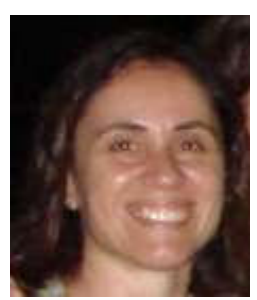

Maria José Pontes received B.S. and M.S. in physics and a Ph.D. in electrical engineering from the State University of Campinas, Brazil, in 1985 1989, and 1996, respectively. In 1996, she joined the Federal University of Technology-Paran, where she has been a Professor with the Electrical Engineering Post Graduation Program working in the field of optical communications. She has also developed software products to optical fiber components and systems, as a Research Scientist with Optiwave Corporation, Canada, 2000- 2002. In 2003, she joined the Electrical Engineering Department, IME, Rio de Janeiro, Brazil, as a Professor, where she has explored optical amplifiers and their applications in optical networks. Since 2006, Dr. Pontes has been with the Department of Electrical Engineering, Federal University of Espírito Santo, Brazil, where she is engaged in the research and development of fiber optical components and sensors. Her research interests also include fiber-optic communication systems.

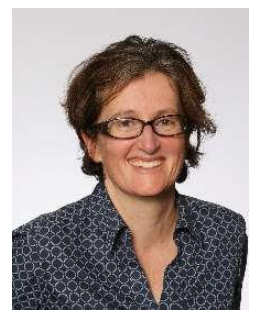

Kate Sugden received the B.Sc. degree in physics from Birmingham University, UK, in 1989 and the M.Sc. degree in optoelectronics and laser Devices from St Andrews University, UK, in 1991 and a Ph.D. in photonics from Aston University, UK in 1996. She returned to the Aston institute of Photonic Technologies in 2004. Since 2018 she has been the Deputy Dean, for Enterprise and International, in the School of Engineering and Applied Science at Aston University. Her current research interests include optical fiber sensing, laser material processing, OCT metrology, laser detections and 3D printing. Professor Sugden is a member of the Institution of Engineering and Technology (IET) and Institute of Physics (IoP) 


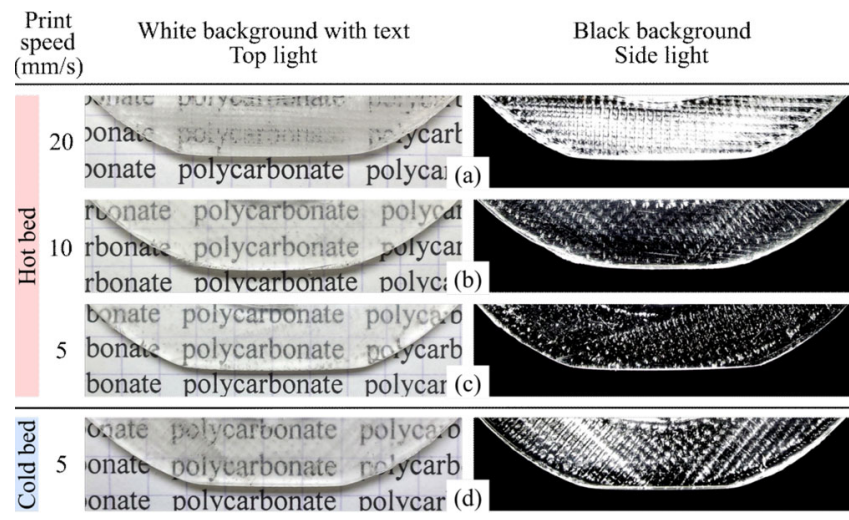

Fig. 1. Comparison of transparency of polished circular test printouts for different print speeds and printing bed temperatures (hot bed $\left(105^{\circ} \mathrm{C}\right)$, cold bed (room temperature)). (Left) Photographs of the samples with front lighting and resting on white squared paper $(5 \mathrm{~mm}$ pitch) with text illustrate the variable transparency of the samples. (Right) Photographs of the same samples on a black background illuminated from the side (the bottom edge of the pictures). This lighting accentuates the density and localization of air voids in the samples.
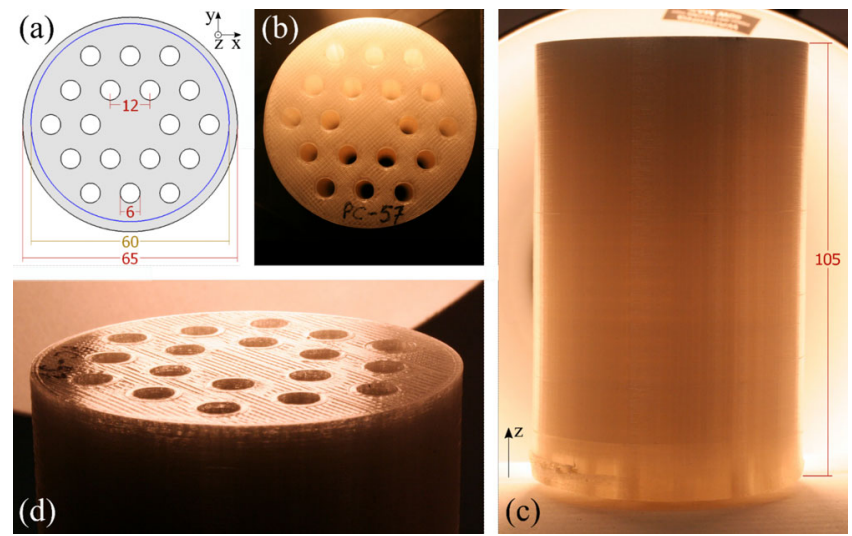

Fig. 2. (a) Top view of the preform design. The blue ring shows the maschined down diameter. (b) Top view of the printed preform (illuminated from the top edge). (c) Side view of the printed preform (illuminated from behind). (d) View of the top surface of the printed preform. All dimensions in $\mathrm{mm}$.
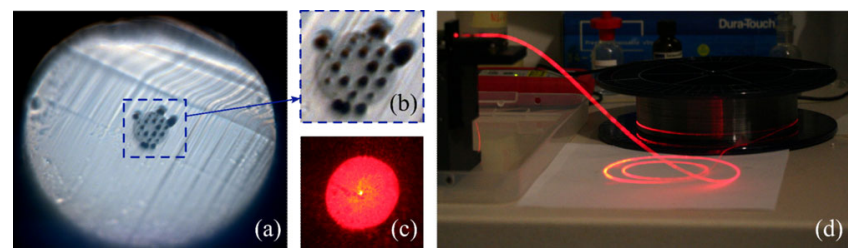

Fig. 3. (a) View of a cleaved fiber facet (blade temperature $=75^{\circ} \mathrm{C}$; fiber outer diameter $=170 \mu \mathrm{m}$, fiber core diameter $=8 \mu \mathrm{m}$ ). (b) Magnified view of the fiber core. (c) Image of a fiber end projected on screen (fiber length of $38.1 \mathrm{~mm}$ ) with clear core guidance. See Fig. 4 for the experimental setup. (d) Photograph of butt-coupling to the fiber on spool.

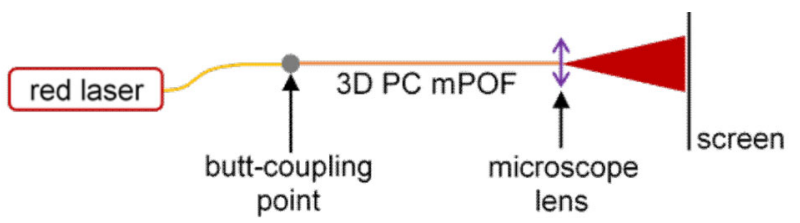

Fig. 4. Schematic showing the experimental setup used for checking core guidance (fiber length $=38.1 \mathrm{~mm}$ ). The image observed on the screen is shown in Fig. 3(c).

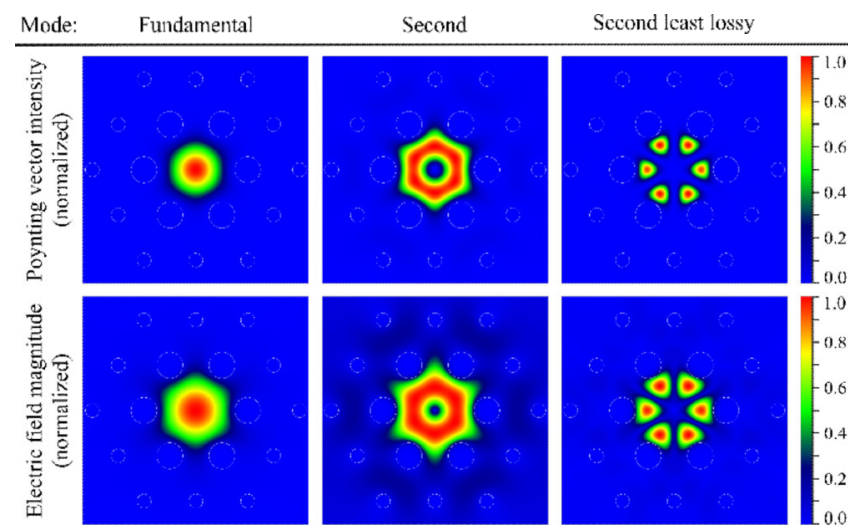

Fig. 5. Poynting vector intensity and electric field magnitude for the fundamental, second and second least lossy modes simulated for 3D PC mPOF at $870 \mathrm{~nm}$ in CUDOS.

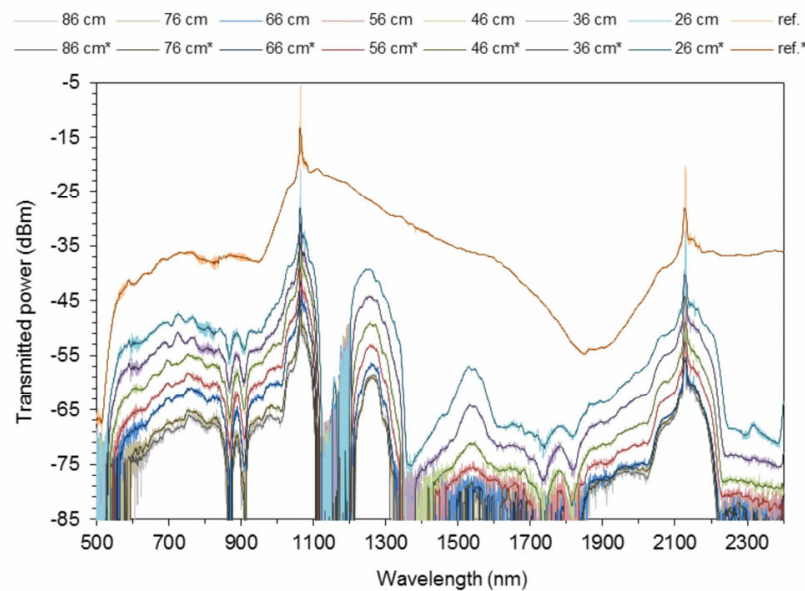

Fig. 6. Transmission spectra for different lengths of the same piece of 3D PC mPOF used for cut-back attenuation calculations. Reference spectrum (marked "ref.") comes from the supercontinuum light source attached directly to OSA. In order to reduce noise, moving averages (darker lines, data series marked with $*$ ) have been plotted over original spectra (lighter lines). In this paper, moving averages for each spectral point have been calculated using 5 neighbors to its left and right, resulting in 11 spectral points being averaged over. 


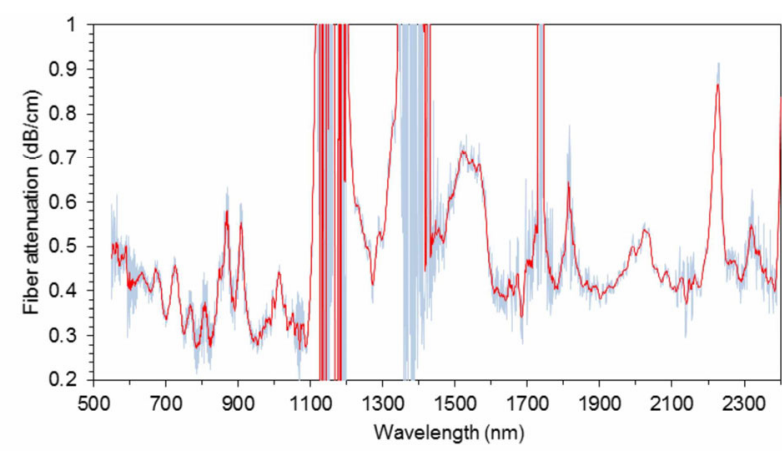

Fig. 7. Attenuation plot of the 3D PC mPOF calculated based on the transmission spectra for the three shortest fiber lengths in Fig. 6 (26, 36, and 46 $\mathrm{cm})$. Moving average (red) of the attenuation has been plotted over the original spectrum (blue) to reduce noise.

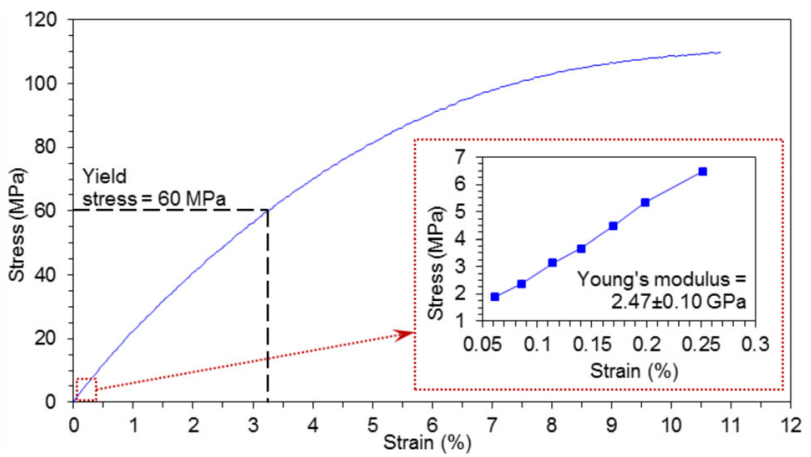

Fig. 8. Stress-strain cycles and Young's modulus of the 3D PC mPOF.
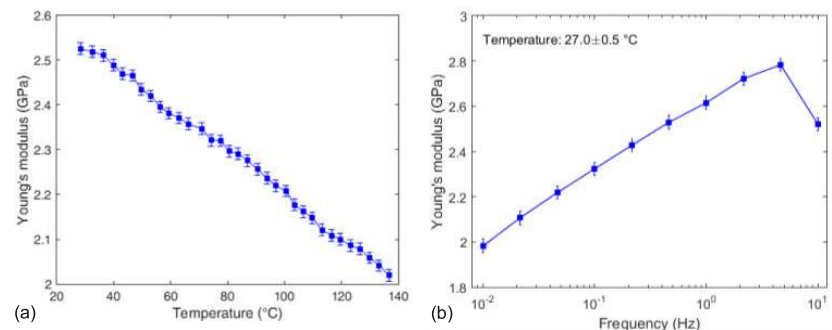

Fig. 9. Young's modulus variation for the 3D PC mPOF as a function of temperature (a) and strain cycle frequency (b). Error bars show mean deviation.

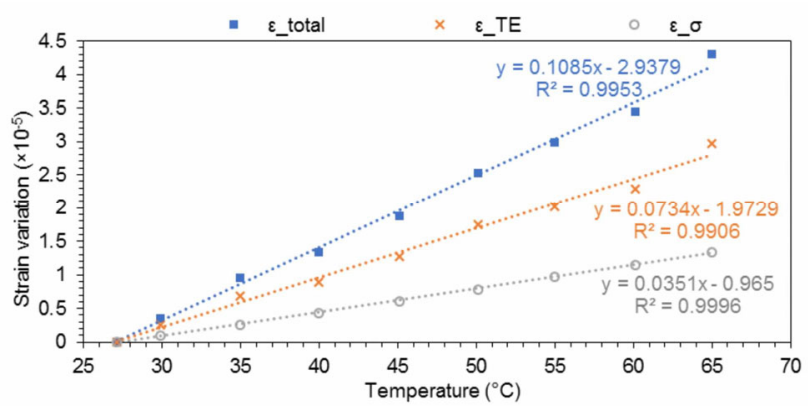

Fig. 10. Strain variation of the 3D PC mPOF $\left(\varepsilon_{\text {total }}\right)$ as a function of temperature. It was split into strain due to thermal expansion $\left(\varepsilon_{T E}\right)$ and different response to stress caused by tensile load of $0.01 \mathrm{~N}$, coming from dependence of Young's modulus on temperature $\left(\varepsilon_{\sigma}\right)$. See (1)-(3) for details.

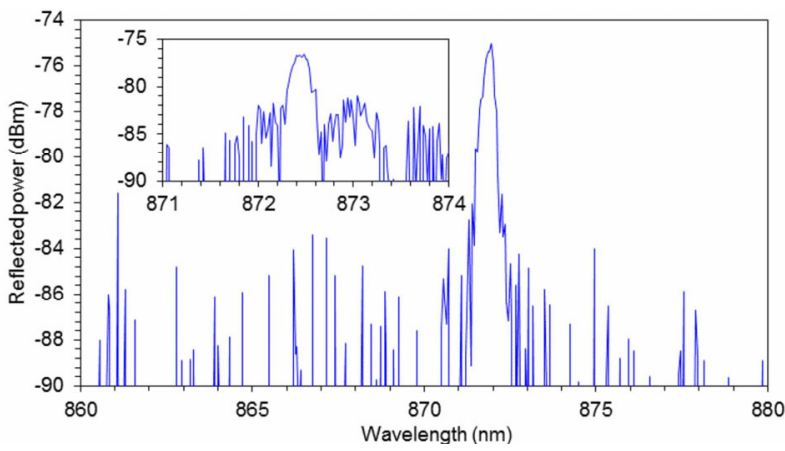

Fig. 11. Reflection spectrum of an FBG (FBG1) inscribed in the 3D PC mPOF using $\mathrm{HeCd} 325 \mathrm{~nm}$ laser. Depending on light coupling conditions, reflection spectrum can display one (main plot) or more peaks (inset).

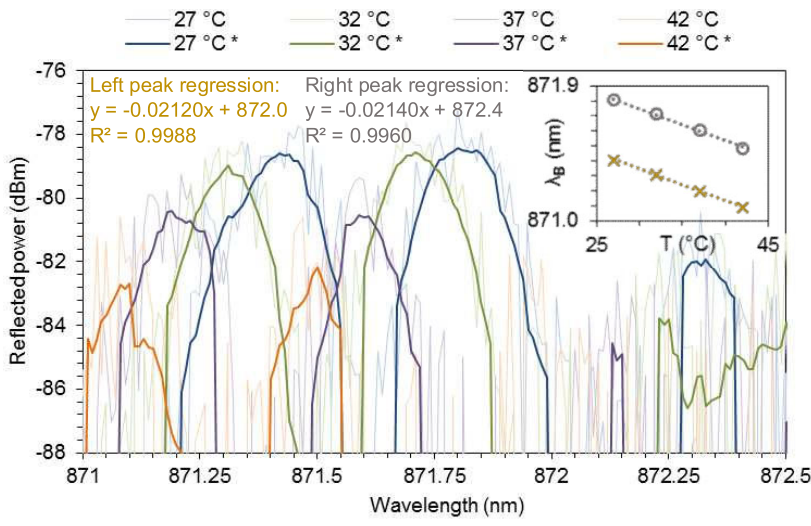

Fig. 12. Spectra of FBG1 recorded at different temperatures. Note two peaks in each spectrum corresponding to two different modes. Temperature sensitivity calculations performed on both peaks gave almost identical results (inset). In order to reduce noise, moving averages (darker lines, data series marked with *) have been plotted over original spectra (lighter lines).

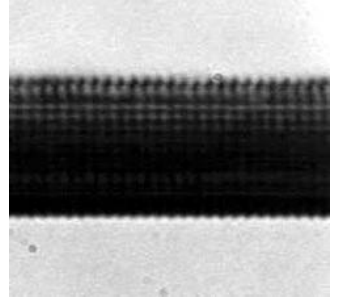

(a)

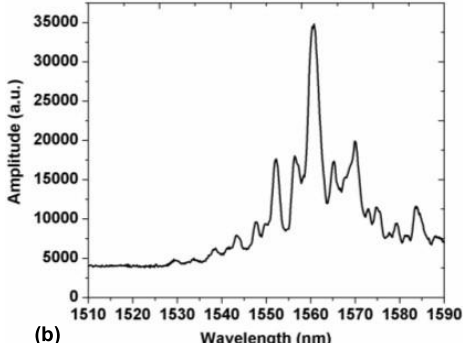

(b)
Fig. 13. (a) Microscopic image (side view) of the FBG inscribed in 3D PC mPOF by femtosecond laser (FBG2). (b) Reflection spectrum (4th order) of FBG2.
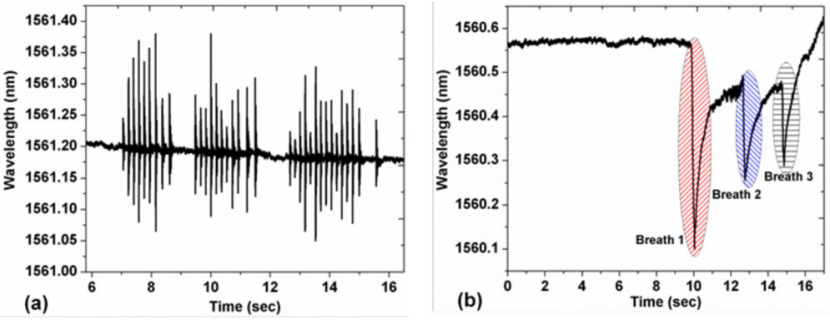

Fig. 14. (a) Time response of FBG2 to vibration induced by hitting the optical table. (b) Time response of the FBG to three breathing shots, resulting in pulses of warmer and more humid air. As shown earlier, the POFBG shows negative temperature sensitivity. The Bragg wavelength increase after $t=15 \mathrm{~s}$ in (b) might be due to positive humidity sensitivity of the fiber [14] 


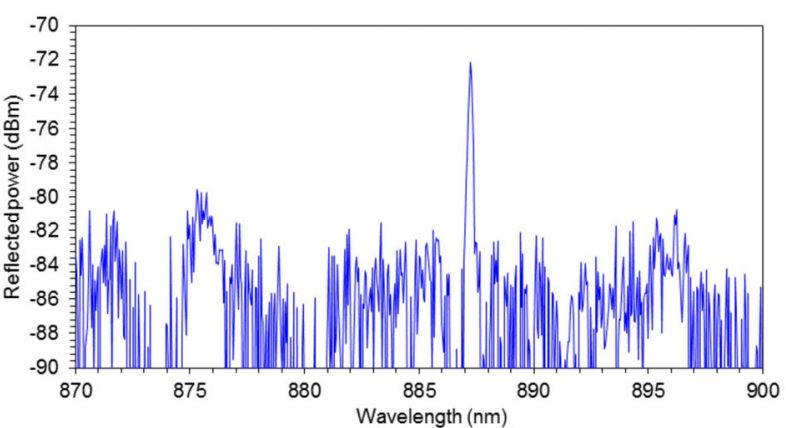

\begin{tabular}{llll}
$\operatorname{Im}\left(n_{\text {eff }}\right)$ & $\begin{array}{l}1.75892967786 \\
\times 10^{-7}\end{array}$ & $\begin{array}{l}3.86335837268 \\
\times 10^{-5}\end{array}$ & $\begin{array}{l}7.15216328426 \\
\times 10^{-6}\end{array}$ \\
$\begin{array}{l}\text { Confinement } \\
\text { loss }(\mathrm{dB} / \mathrm{cm})\end{array}$ & 0.11033757 & 24.23482671 & 4.48654826 \\
\hline & \multicolumn{2}{l}{ Wavelength $=1550 \mathrm{~nm}$} & \\
\cline { 2 - 4 } $\operatorname{Re}\left(n_{\text {eff }}\right)$ & 1.56194339477 & 1.55462887006 & 1.52603245572 \\
$\operatorname{Im}\left(n_{\text {eff }}\right)$ & $\begin{array}{l}1.23636037073 \\
\times 10^{-6}\end{array}$ & $\begin{array}{l}1.50868839412 \\
\times 10^{-4}\end{array}$ & $\begin{array}{l}5.90364581028 \\
\times 10^{-5}\end{array}$ \\
$\begin{array}{l}\text { Confinement } \\
\operatorname{loss}(\mathrm{dB} / \mathrm{cm})\end{array}$ & 0.4353189302 & 53.1204843936 & 20.7865670839 \\
\hline
\end{tabular}

Fig. 15. Reflection spectrum of a $248 \mathrm{~nm} \mathrm{KrF}$ laser-inscribed FBG in the 3D PC mPOF.

Table I.

RESULTS OF CUDOS SIMULATIONS FOR FUNDAMENTAL, SECOND AND SECOND LEAST LOSSY MODES FOR 870 NM AND 1550 NM

\begin{tabular}{|c|c|c|c|}
\hline Mode & Fundamental & Second & $\begin{array}{l}\text { Second least } \\
\text { lossy }\end{array}$ \\
\hline Mode class & $\begin{array}{l}3 / 4 \\
\text { (degenerate) }\end{array}$ & $\begin{array}{l}2 \text { (non- } \\
\text { degenerate) }\end{array}$ & $\begin{array}{l}5 / 6 \\
\text { (degenerate) }\end{array}$ \\
\hline $\begin{array}{l}\text { Step-index fiber } \\
\text { equivalent }\end{array}$ & $\begin{array}{l}\mathrm{HE}_{11} \text { (circular } \\
\text { symmetry) }\end{array}$ & $\begin{array}{l}\mathrm{TE}_{01} \text { (circular } \\
\text { symmetry) }\end{array}$ & $\begin{array}{l}\mathrm{E}^{\mathrm{x} / \mathrm{y}}{ }_{23} \\
\text { (rectangular } \\
\text { symmetry) }\end{array}$ \\
\hline & \multicolumn{3}{|c|}{ Wavelength $=870 \mathrm{~nm}$} \\
\hline $\operatorname{Re}\left(n_{e f f}\right)$ & 1.57535279891 & 1.57296137794 & 1.56379542212 \\
\hline
\end{tabular}

Table II.

COMPARISON OF ATTENUATION (DB/CM) OF SOLID-CORE POFS FROM 3D-PRINTED AND DRILLED PREFORMS ${ }^{a}$

\begin{tabular}{|c|c|c|c|c|c|c|}
\hline \multirow[b]{2}{*}{ Wavelength (nm) } & \multicolumn{4}{|c|}{ 3D-printed preforms } & \multicolumn{2}{|c|}{ Drilled preforms } \\
\hline & $\begin{array}{l}\text { SI-POF [4] } \\
(\mathrm{PC}+\mathrm{ABS})\end{array}$ & $\begin{array}{l}\text { Air-structured POF [5] } \\
\text { (SBP) }\end{array}$ & $\begin{array}{l}\text { SI-POF [3], } \\
\text { (SBP+PETG) }\end{array}$ & 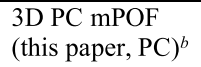 & $\begin{array}{l}\mathrm{mPOF}[13] \\
(\mathrm{PC})\end{array}$ & $\begin{array}{l}\text { Optimized mPOF [14] } \\
\text { (PC) }\end{array}$ \\
\hline 543 & & & 0.64 & 0.53 & & \\
\hline $632-633$ & $0.7-1.8^{c}$ & $\sim 1.5$ & & 0.44 & 0.16 & 0.055 \\
\hline 819 & & & & 0.29 & & 0.041 \\
\hline 833.5 & & & & 0.32 & 0.089 & \\
\hline $1047-1052$ & & & 0.44 & $\sim 0.34^{d}$ & & \\
\hline 1064 & & $\sim 0.75$ & & 0.33 & & \\
\hline $1520-1560$ & & & 0.94 & $\sim 0.68^{d}$ & & \\
\hline 1550 & & $\sim 1.51$ & & 0.69 & & \\
\hline
\end{tabular}

${ }^{a}$ Fiber materials are given in brackets after fiber name; for step-index (SI) fibers, both core and cladding materials, respectively, are given. ${ }^{b}$ For full attenuation spectrum, see Fig. $7 .{ }^{c}$ Attenuation depending on $3 \mathrm{D}$-printed core shape: square core $-1.2 \mathrm{~dB} / \mathrm{cm}$; triangular core $-1.3 \mathrm{~dB} / \mathrm{cm}$; rectangular core $-1.8 \mathrm{~dB} / \mathrm{cm}$. Attenuation of $0.7 \mathrm{~dB} / \mathrm{cm}$ measured for circular core of solid material (not 3D-printed). ${ }^{d}$ Average values for the wavelength range.

[1] S. H. Huang, P. Liu, A. Mokasdar, and L. Hou, "Additive manufacturing and its societal impact: A literature review," (in English), International Journal of Advanced Manufacturing Technology, Review vol. 67, no. 5-8, pp. 1191-1203, 2013.

[2] T. J. Horn and O. L. A. Harrysson, "Overview of current additive manufacturing technologies and selected applications," (in English), Science Progress, Article vol. 95, no. 3, pp. 255-282, 2012.

[3] K. Cook et al., "Step-index optical fiber drawn from 3D printed preforms," (in English), Optics Letters, vol. 41, no. 19, pp. 4554-4557, Oct 12016. 
[4] Q. K. Zhao et al., "Optical fibers with special shaped cores drawn from 3D printed preforms," (in English), Optik, vol. 133, pp. 60-65, 2017.

[5] K. Cook et al., "Air-structured optical fiber drawn from a 3D-printed preform," Opt Lett, vol. 40, no. 17, pp. 3966-9, Sep 12015.

[6] M. G. Zubel, A. Fasano, G. Woyessa, K. Sugden, H. K. Rasmussen, and O. Bang, "3D-printed PMMA preform for hollow-core POF drawing," presented at the 25th International Conference on Plastic Optical Fibres, POF 2016, Birmingham, United Kingdom, 2017. Conference Paper. Available: https://www.scopus.com/inward/record.uri?eid=2$\underline{\mathrm{s} 2.0-85021399589 \& \text { partnerID }=40 \& \mathrm{md} 5=3 \mathrm{~d} 3 \mathrm{df} 47198 \mathrm{~b} 277 \mathrm{f} 4 \mathrm{~b} 69254796167947 \mathrm{~b}}$

[7] T. H. R. Marques, B. M. Lima, J. H. Osorio, L. E. da Silva, and C. M. B. Cordeiro, "3D Printed Microstructured Optical Fibers," presented at the 2017 SBMO/IEEE MTT-S International Microwave and Optoelectronics Conference (Imoc), 2017. Available: $\leq$ Go to ISI $>$ ://WOS:000419280400078

[8] W. Talataisong et al., "Mid-IR Hollow-core microstructured fiber drawn from a 3D printed PETG preform," (in English), Scientific Reports, vol. 8, May 252018.

[9] J. Canning, M. A. Hossain, C. Y. Han, L. Chartier, K. Cook, and T. Athanaze, "Drawing optical fibers from threedimensional printers," (in English), Optics Letters, vol. 41, no. 23, pp. 5551-5554, Dec 12016.

[10] S. Li et al., "A $0.1 \mathrm{THz}$ low-loss 3D printed hollow waveguide," Optik, vol. 176, pp. 611-616, 2019/01/01/ 2019.

[11] S. Pandey, B. Gupta, and A. Nahata, "Terahertz plasmonic waveguides created via 3D printing," Optics Express, vol. 21, no. 21, pp. 24422-24430, 2013/10/21 2013.

[12] A. L. S. Cruz, C. M. B. Cordeiro, and M. A. R. Franco, "3D Printed Hollow-Core Terahertz Fibers," Fibers, vol. 6, no. 3, p. 43, 2018.

[13] A. Fasano et al., "Fabrication and characterization of polycarbonate microstructured polymer optical fibers for hightemperature-resistant fiber Bragg grating strain sensors," (in English), Optical Materials Express, vol. 6, no. 2, pp. 649659, Feb 12016.

[14] G. Woyessa, A. Fasano, C. Markos, H. K. Rasmussen, and O. Bang, "Low Loss Polycarbonate Polymer Optical Fiber for High Temperature FBG Humidity Sensing," (in English), IEEE Photonics Technology Letters, vol. 29, no. 7, pp. 575-578, Apr 12017.

[15] C. Markos, A. Stefani, K. Nielsen, H. K. Rasmussen, W. Yuan, and O. Bang, "High-T-g TOPAS microstructured polymer optical fiber for fiber Bragg grating strain sensing at 110 degrees," Optics Express, vol. 21, no. 4, pp. 47584765, 2013.

[16] G. Woyessa, A. Fasano, C. Markos, A. Stefani, H. K. Rasmussen, and O. Bang, "Zeonex microstructured polymer optical fiber: fabrication friendly fibers for high temperature and humidity insensitive Bragg grating sensing," (in English), Optical Materials Express, vol. 7, no. 1, pp. 286-295, Jan 12017.

[17] K. E. Carroll, C. Zhang, D. J. Webb, K. Kalli, A. Argyros, and M. C. Large, "Thermal response of Bragg gratings in PMMA microstructured optical fibers.," Optics express, vol. 15, no. 14, pp. 8844-50, 2007.

[18] D. Celentano, D. Wimmer, L. Colabella, and A. P. Cisilino, "Viscoelastic mechanical characterization of a short-fiber reinforced polyethylene tube: Experiments and modelling," (in English), International Journal of Pressure Vessels and Piping, vol. 134, pp. 82-91, Oct 2015.

[19] S. Ropers, M. Kardos, and T. A. Osswald, "A thermo-viscoelastic approach for the characterization and modeling of the bending behavior of thermoplastic composites," (in English), Composites Part a-Applied Science and Manufacturing, vol. 90 , pp. 22-32, Nov 2016.

[20] T. C. Henry, C. E. Bakis, and E. C. Smith, "Viscoelastic characterization and self-heating behavior of laminated fiber composite driveshafts," (in English), Materials \& Design, vol. 66, pp. 346-355, Feb 52015.

[21] I. K. Lin, K. S. Ou, Y. M. Liao, Y. Liu, K. S. Chen, and X. Zhang, "Viscoelastic Characterization and Modeling of Polymer Transducers for Biological Applications," (in English), Journal of Microelectromechanical Systems, vol. 18, no. 5, pp. 1087-1099, Oct 2009.

[22] A. Stefani, S. Andresen, W. Yuan, and O. Bang, "Dynamic Characterization of Polymer Optical Fibers," (in English), IEEE Sensors Journal, vol. 12, no. 10, pp. 3047-3053, Oct 2012.

[23] A. G. Leal, C. Marques, A. Frizera, and M. J. Pontes, "Dynamic Mechanical Analysis on a PolyMethyl Methacrylate (PMMA) Polymer Optical Fiber," (in English), IEEE Sensors Journal, vol. 18, no. 6, pp. 2353-2361, Mar 152018.

[24] A. Leal et al., "Dynamic mechanical characterization with respect to temperature, humidity, frequency and strain in mPOFs made of different materials," (in English), Optical Materials Express, vol. 8, no. 4, pp. 804-815, Apr 12018. A. Leal et al., "Dynamic mechanical analysis on fused polymer optical fibers: towards sensor applications," (in English), Optics Letters, vol. 43, no. 8, pp. 1754-1757, Apr 152018.

[26] D. J. Webb, "Polymer Fibre Bragg Grating Sensors and their Applications," in Optical Fiber Sensors: Advanced Techniques and Applications, G. Rajan, Ed. United Kingdom: CRC Press, 2015, p. 576.

[27] M. G. Zubel, K. Sugden, D. Saez-Rodriguez, K. Nielsen, and O. Bang, "3-D printed sensing patches with embedded polymer optical fibre Bragg gratings," presented at the Sixth European Workshop on Optical Fibre Sensors (EWOFS'2016), Limerick, Ireland, 2016. Available: $\leq$ Go to ISI >://WOS:000378434400085 
https://www.spiedigitallibrary.org/conference-proceedings-of-spie/9916/99162E/3D-printed-sensing-patches-with-embeddedpolymer-optical-fibre-Bragg/10.1117/12.2237495.pdf

[28] M. G. Zubel, K. Sugden, D. J. Webb, D. Saez-Rodriguez, K. Nielsen, and O. Bang, "Embedding silica and polymer fibre Bragg gratings (FBG) in plastic 3D-printed sensing patches," presented at the Micro-Structured and Specialty Optical Fibres IV, SPIE Photonics Europe 2016, Brussels, Belgium, 2016. Available: $\leq$ Go to ISI >://WOS:000389681800014

https://www.spiedigitallibrary.org/conference-proceedings-of-spie/9886/98860N/Embedding-silica-and-polymer-fibre-Bragggratings-FBG-in-plastic/10.1117/12.2228753.pdf

[29] A. Pospori et al., "Annealing effects on strain and stress sensitivity of polymer optical fibre based sensors," presented at the Micro-Structured and Specialty Optical Fibres IV, SPIE Photonics Europe 2016, Brussels, Belgium, 2016. Available: $\leq$ Go to ISI $>$ ://WOS:000389681800020

https://www.spiedigitallibrary.org/conference-proceedings-of-spie/9886/98860V/Annealing-effects-on-strain-and-stresssensitivity-of-polymer-optical/10.1117/12.2227473.pdf

[30] J. Bonefacino, X. Cheng, C.-F. J. Pun, S. T. Boles, and H.-Y. Tam, "Impact of high UV fluences on the mechanical and sensing properties of polymer optical fibers for high strain measurements," Optics Express, vol. 28, no. 2, pp. 1158$1167,2020 / 01 / 202020$.

[31] A. Lacraz et al., "Embedding low loss polymer optical fibre Bragg gratings: Two different approaches," presented at the 25th International Conference on Plastic Optical Fibres, POF 2016, Birmingham, United Kingdom, 2017. Conference Paper. Available: https://www.scopus.com/inward/record.uri?eid=2-s2.085021440609\&partnerID=40\&md5=f0aad307554b0e511be3674b62019d16

[32] F. Berghmans et al., "Photonic skins for optical sensing: Highlights of the PHOSFOS Project," presented at the 20th International Conference on Optical Fibre Sensors, Edinburgh, United Kingdom, 2009. Available: http://www.scopus.com/inward/record.url?eid=2-s2.070449389816\&partnerID=40\&md5=37a5766e0f9db559b31add0c51cec37d

http://proceedings.spiedigitallibrary.org/data/Conferences/SPIEP/10273/75030B 1.pdf

[33] X. Chen et al., "Polymer photonic sensing skin," presented at the 4th European Workshop on Optical Fibre Sensors, Porto, Portugal, 2010. Available: http://www.scopus.com/inward/record.url?eid=2-s2.0$77957832408 \&$ partnerID $=40 \&$ md5=e2e $575568 \mathrm{fb} 14 \mathrm{~b} 113 \mathrm{~d} 1588 \mathrm{ad} 32 \mathrm{c} 3 \mathrm{bdfa}$

http://proceedings.spiedigitallibrary.org/data/Conferences/SPIEP/7543/76533A 1.pdf

[34] Y. Mizuno, R. Ishikawa, H. Lee, A. Theodosiou, K. Kalli, and K. Nakamura, "Potential of discriminative sensing of strain and temperature using perfluorinated polymer FBG," IEEE Sensors Journal, pp. 1-1, 2019.

[35] G. Woyessa et al., "Zeonex-PMMA microstructured polymer optical FBGs for simultaneous humidity and temperature sensing," (in English), Optics Letters, vol. 42, no. 6, pp. 1161-1164, Mar 152017.

[36] G. Woyessa, K. Nielsen, A. Stefani, C. Markos, and O. Bang, "Temperature insensitive hysteresis free highly sensitive polymer optical fiber Bragg grating humidity sensor," Optics Express, vol. 24, no. 2, pp. 1206-1213, 2016/01/25 2016.

[37] A. Pospori, C. A. F. Marques, D. Saez-Rodriguez, K. Nielsen, O. Bang, and D. J. Webb, "Sensitivity enhancement using annealed polymer optical fibre based sensors for pressure sensing applications," presented at the Sixth European Workshop on Optical Fibre Sensors (EWOFS'2016), Limerick, Ireland, 2016. Available: $\leq$ Go to ISI $>$ ://WOS:000378434400013

https://www.spiedigitallibrary.org/conference-proceedings-of-spie/9916/99160E/Sensitivity-enhancement-using-annealedpolymer-optical-fibre-based-sensors-for/10.1117/12.2236877.pdf

[38] R. Ishikawa et al., "Pressure Dependence of Fiber Bragg Grating Inscribed in Perfluorinated Polymer Fiber," IEEE Photonics Technology Letters, vol. 29, no. 24, pp. 2167-2170, 2017.

[39] X. Cheng, Y. Liu, and C. Yu, "Gas Pressure Sensor Based on BDK-Doped Polymer Optical Fiber," Micromachines, vol. 10, no. 11, p. 717, 2019.

[40] W. Zhang, D. Webb, and G. Peng, "Polymer optical fiber Bragg grating acting as an intrinsic biochemical concentration sensor," (in English), Optics Letters, vol. 37, no. 8, pp. 1370-1372, 2012.

[41] A. Stefani, S. Andresen, W. Yuan, N. Herholdt-Rasmussen, and O. Bang, "High Sensitivity Polymer Optical FiberBragg-Grating-Based Accelerometer," (in English), IEEE Photonics Technology Letters, vol. 24, no. 9, pp. 763-765, May 12012.

[42] G. Woyessa et al., "Single mode step-index polymer optical fiber for humidity insensitive high temperature fiber Bragg grating sensors," (in English), Optics Express, vol. 24, no. 2, pp. 1253-1260, Jan 252016.

[43] C. A. F. Marques, A. Pospori, and D. J. Webb, "Time-dependent variation of POF Bragg grating reflectivity and wavelength submerged in different liquids," (in English), Optics and Laser Technology, vol. 94, pp. 234-239, Sep 1 2017.

[44] C. Broadway et al., "A Compact Polymer Optical Fibre Ultrasound Detector," presented at the Photons Plus Ultrasound: Imaging and Sensing 2016, SPIE BiOS, , San Francisco, California, United States, 2016. Available: $\leq$ Go to ISI > ://WOS:000378437000036 
https://www.spiedigitallibrary.org/conference-proceedings-of-spie/9708/970813/A-compact-polymer-optical-fibre-ultrasounddetector/10.1117/12.2212420.pdf

[45] C. Broadway et al., "Microstructured polymer optical fibre sensors for opto-acoustic endoscopy," presented at the Micro-Structured and Specialty Optical Fibres IV, SPIE Photonics Europe 2016, Brussels, Belgium, 2016. Available: $\leq$ Go to ISI $>$ ://WOS:000389681800018

https://www.spiedigitallibrary.org/conference-proceedings-of-spie/9886/98860S/Microstructured-polymer-optical-fibre-sensorsfor-opto-acoustic-endoscopy/10.1117/12.2227588.pdf

[46] C. Broadway et al., "L-band CYTOP Bragg gratings for ultrasound sensing," presented at the Micro-Structured and Specialty Optical Fibres V, SPIE Photonics Europe, Strasbourg, France, 2018.

[47] W. Zhang and D. J. Webb, "Polymer optical fiber grating as water activity sensor," in Micro-Structured and Specialty Optical Fibres III, SPIE Photonics Europe, Brussels, Belgium, 2014, vol. 9128: SPIE.

[48] C. A. F. Marques, G. D. Peng, and D. J. Webb, "Highly sensitive liquid level monitoring system utilizing polymer fiber Bragg gratings," (in English), Optics Express, vol. 23, no. 5, pp. 6058-6072, Mar 92015.

[49] P. Stajanca and K. Krebber, "Radiation-Induced Attenuation of Perfluorinated Polymer Optical Fibers for Radiation Monitoring," (in English), Sensors, vol. 17, no. 9, Sep 2017.

[50] C. C. Ye et al., "Applications of polymer optical fibre grating sensors to condition monitoring of textiles," in 20th International Conference on Optical Fibre Sensors, Edinburgh, 2009, vol. 7503.

[51] M. C. J. Large, L. Poladian, G. W. Barton, and M. A. Van Eijkelenborg, Microstructured polymer optical fibres. Springer US, 2008.

[52] A. Stefani, K. Nielsen, H. K. Rasmussen, and O. Bang, "Cleaving of TOPAS and PMMA microstructured polymer optical fibers: Core-shift and statistical quality optimization," Optics Communications, vol. 285, no. 7, pp. 1825-1833, 2012/04/01/ 2012.

[53] S. H. Law et al., "Cleaving of microstructured polymer optical fibres," Optics Communications, vol. 258, no. 2, pp. 193202, 2006.

[54] S. H. Law, M. A. van Eijkelenborg, G. W. Barton, C. Yan, R. Lwin, and J. Gan, "Cleaved end-face quality of microstructured polymer optical fibres," Optics Communications, vol. 265, no. 2, pp. 513-520, 2006/09/15/2006.

[55] B. T. Kuhlmey, R. C. McPhedran, and C. M. de Sterke, "Modal cutoff in microstructured optical fibers," Optics Letters, vol. 27, no. 19, pp. 1684-1686, 2002/10/01 2002.

[56] F. Zolla et al., Foundations of Photonic Crystal Fibres. IMPERIAL COLLEGE PRESS, 2011, p. 552.

[57] "COMSOL v. 4.3," 4.3 ed. www.comsol.com: COMSOL AB, Stockholm, Sweden.

[58] T. P. White et al., "Multipole method for microstructured optical fibers. I. Formulation," Journal of the Optical Society of America B, vol. 19, no. 10, pp. 2322-2330, 2002/10/01 2002.

[59] B. T. Kuhlmey et al., "Multipole method for microstructured optical fibers. II. Implementation and results," Journal of the Optical Society of America B, vol. 19, no. 10, pp. 2331-2340, 2002/10/01 2002.

[60] B. T. Kuhlmey, "CUDOS MOF Utilities v. 2.1," Fibre 2.1.2.2, WinField 2.1.2.6 ed. http://www.physics.usyd.edu.au/cudos/mofsoftware/index.html.

[61] P. McIsaac, "Symmetry-Induced Modal Characteristics of Uniform Waveguides - I: Summary of Results," IEEE Transactions on Microwave Theory and Techniques, vol. 23, no. 5, pp. 421-429, 1975.

[62] R. Syms and J. Cozens, Optical Guided Waves and Devices. London, United Kingdom: McGraw-Hill Education Europe, 1992, p. 500.

[63] (2003, 11 Jul 2018). Materials Data Book. Available: http://wwwmdp.eng.cam.ac.uk/web/library/enginfo/cueddatabooks/materials.pdf

[64] H. K. Rasmussen, A. Fasano, P. Stajanca, G. Woyessa, M. Schukar, and O. Bang, "Mechanical characterization of drawn Zeonex, Topas, polycarbonate and PMMA microstructured polymer optical fibres," Optical Materials Express, vol. 8, no. 11,pp. 3600-3614, 2018/11/01 2018.

[65] R. M. Waxler, D. Horowitz, and A. Feldman, "Optical and physical parameters of Plexiglas 55 and Lexan," Applied Optics, vol. 18, no. 1, pp. 101-104, 1979/01/01 1979.

[66] Z. Zhang, P. Zhao, P. Lin, and F. Sun, "Thermo-optic coefficients of polymers for optical waveguide applications," Polymer, vol. 47, no. 14, pp. 4893-4896, 2006/06/28/ 2006.

[67] P. A. Soave, R. A. F. Dau, M. R. Becker, M. B. Pereira, and F. Horowitz, "Refractive index control in bicomponent polymer films for integrated thermo-optical applications," Optical Engineering, vol. 48, no. 12, pp. 1-6, 2009.

[68] M. R. Saleem, S. Honkanen, and J. Turunen, "Thermo-optic coefficient of Ormocomp and comparison of polymer materials in athermal replicated subwavelength resonant waveguide gratings," Optics Communications, vol. 288, pp. 5665, 2013/02/01/ 2013.

[69] G. Khanarian, "Optical properties of cyclic olefin copolymers," Optical Engineering, vol. 40, no. 6, pp. 1024-1029, 2001.

[70] Y. Sato, Y. Yamasaki, S. Takishima, and H. Masuoka, "Precise measurement of the PVT of polypropylene and polycarbonate up to $330^{\circ} \mathrm{C}$ and $200 \mathrm{MPa}$," Journal of Applied Polymer Science, vol. 66, no. 1, pp. 141-150, 1997. 
[71] (4 Apr 2019). MATWEB: Overview of materials for Polycarbonate, Extruded. Available: http://matweb.com/search/DataSheet.aspx?MatGUID=501acbb63cbc4f748faa7490884cdbca

[72] W. Yuan et al., "Humidity insensitive TOPAS polymer fiber Bragg grating sensor," Optics Express, vol. 19, no. 20, pp. 19731-19739, 2011/09/26 2011.

[73] X. Cheng et al., "High-sensitivity temperature sensor based on Bragg grating in BDK-doped photosensitive polymer optical fiber," Chinese Optics Letters, vol. 9, no. 2, p. 020602, 2011/02/10 2011.

[74] G.-D. Peng and P. L. Chu, "Polymer optical fiber sensing," presented at the Optical Information Processing Technology, Photonics Asia, Shanghai, China, 2002. Available: https://doi.org/10.1117/12.483228

[75] A. Bar-Cohen, B. Han, and K. Joon Kim, "Thermo-Optic Effects in Polymer Bragg Gratings," in Micro- and OptoElectronic Materials and Structures: Physics, Mechanics, Design, Reliability, Packaging, E. Suhir, Y. C. Lee, and C. P. Wong, Eds. Boston, MA: Springer US, 2007, pp. A65-A110.

[76] W. Zhang and D. J. Webb, "Factors influencing the temperature sensitivity of PMMA based optical fiber Bragg gratings," presented at the Micro-structured and Specialty Optical Fibres III, SPIE Photonics Europe, Brussels, Belgium, 2014. Available: https://doi.org/10.1117/12.2054210

[77] I. M. Ward, "The preparation, structure and properties of ultra-high modulus flexible polymers," Advances in Polymer Science, pp. 1-70, 1985.

[78] V. B. Gupta, "Nature of the Crystalline and Amorphous Phases in Oriented Polymers and Their Influence on Physical Properties," in Oriented Polymer Materials, S. Fakirov, Ed.: WILEY-VCH Verlag, 2008.

[79] R. Schledjewski and K. Friedrich, "Orientation Effects on the Thermal, Mechanical and Tribological Performance of Neat, Reinforced and Blended Liquid Crystalline Polymers," in Oriented Polymer Materials, S. Fakirov, Ed.: WILEYVCH Verlag, 2008.

[80] H. Dobb, D. J. Webb, K. Kalli, A. Argyros, M. C. J. Large, and M. a. van Eijkelenborg, "Continuous wave ultraviolet light-induced fiber Bragg gratings in few- and single-mode microstructured polymer optical fibers," Optics letters, vol. 30, no. 24, pp. 3296-8, 2005.

[81] G. Woyessa, "Speciality and microstructured polymer optical FBG sensors," PhD Ph.D. thesis, Technical University of Denmark, Copenhagen, Denmark, 2017.

[82] A. Rosenberg, S. H. Lee, J. S. Shirk, and G. Beadie, "Opto-thermal characteristics of amorphous polyimides for optical applications," Optical Materials Express, vol. 8, no. 8, pp. 2159-2172, 2018/08/01 2018.

[83] J. M. Cariou, J. Dugas, L. Martin, and P. Michel, "Refractive-index variations with temperature of PMMA and polycarbonate," Applied Optics, vol. 25, no. 3, pp. 334-336, 1986/02/01 1986.

[84] R. S. Moshrefzadeh, M. D. Radcliffe, T. C. Lee, and S. K. Mohapatra, "Temperature dependence of index of refraction of polymeric waveguides," Journal of Lightwave Technology, vol. 10, no. 4, pp. 420-425, 1992.

[85] J.-g. Chen et al., "Low-loss planar optical waveguides fabricated from polycarbonate," Polymer Engineering \& Science, vol. 49, no. 10, pp. 2015-2019, 2009/10/01 2009.

[86] A. Theodosiou, A. Lacraz, A. Stassis, C. Koutsides, M. Komodromos, and K. Kalli, "Plane-by-Plane Femtosecond Laser Inscription Method for Single-Peak Bragg Gratings in Multimode CYTOP Polymer Optical Fiber," (in English), Journal of Lightwave Technology, vol. 35, no. 24, pp. 5404-5410, Dec 152017.

[87] A. Theodosiou, X. H. Hu, C. Caucheteur, and K. Kalli, "Bragg Gratings and Fabry-Perot Cavities in Low-Loss Multimode CYTOP Polymer Fiber," (in English), IEEE Photonics Technology Letters, vol. 30, no. 9, pp. 857-860, May 12018 .

[88] A. Ioannou, A. Theodosiou, C. Caucheteur, and K. Kalli, "Direct writing of plane-by-plane tilted fiber Bragg gratings using a femtosecond laser," (in English), Optics Letters, vol. 42, no. 24, pp. 5198-5201, Dec 152017. 